\title{
Free and Forced Vibration of the Moderately Thick Laminated Composite Rectangular Plate on Various Elastic Winkler and Pasternak Foundations
}

\author{
Dongyan Shi, ${ }^{1}$ Hong Zhang, ${ }^{1}$ Qingshan Wang, ${ }^{1,2,3}$ and Shuai Zha ${ }^{1}$ \\ ${ }^{1}$ College of Mechanical and Electrical Engineering, Harbin Engineering University, Harbin 150001, China \\ ${ }^{2}$ College of Mechanical and Electrical Engineering, Central South University, Changsha 410083, China \\ ${ }^{3}$ State Key Laboratory of High Performance Complex Manufacturing, Central South University, Changsha 410083, China
}

Correspondence should be addressed to Qingshan Wang; wangqingshanxlz@hotmail.com

Received 26 February 2017; Revised 9 May 2017; Accepted 17 May 2017; Published 11 July 2017

Academic Editor: Hassan Askari

Copyright (C) 2017 Dongyan Shi et al. This is an open access article distributed under the Creative Commons Attribution License, which permits unrestricted use, distribution, and reproduction in any medium, provided the original work is properly cited.

\begin{abstract}
An improved Fourier series method (IFSM) is applied to study the free and forced vibration characteristics of the moderately thick laminated composite rectangular plates on the elastic Winkler or Pasternak foundations which have elastic uniform supports and multipoints supports. The formulation is based on the first-order shear deformation theory (FSDT) and combined with artificial virtual spring technology and the plate-foundation interaction by establishing the two-parameter foundation model. Under the framework of this paper, the displacement and rotation functions are expressed as a double Fourier cosine series and two supplementary functions which have no relations to boundary conditions. The Rayleigh-Ritz technique is applied to solve all the series expansion coefficients. The accuracy of the results obtained by the present method is validated by being compared with the results of literatures and Finite Element Method (FEM). In this paper, some results are obtained by analyzing the varying parameters, such as different boundary conditions, the number of layers and points, the spring stiffness parameters, and foundation parameters, which can provide a benchmark for the future research.
\end{abstract}

\section{Introduction}

A variety of composite plates on the elastic foundations are widely used in civil engineering, like rigid road plate, airport pavement, building foundations, dock platform, and so on. It is of great significance for design, use, and maintenance to study the mechanical properties of composite plates on elastic foundation. Therefore, the study on the vibration characteristics of laminated plates on the elastic foundations has been one of the hot spots in recent years. According to the existing research, the elastic foundational plate models can be divided into two categories which are Winkler-type foundation and two-parameter foundation.

Winkler foundation is the first proposed linear elastic theoretical model. Laura et al. [1] solved the free vibrations of a circular thin plate on Winkler foundation with varying thickness by using linear analysis and the Rayleigh-Schmidt method. Liew et al. [2] extended an approximate analysis of rectangular Mindlin plates resting on Winkler foundations based on the differential quadrature method (DQM). The plates were subject to arbitrary combination of free, simply supported, and clamped boundary conditions. Gupta et al. [3] discussed the effect of Winkler foundation on axisymmetric vibrations of polar orthotropic circular plates with variable thickness based on the classical plate theory. Xiang [4] investigated the effect of multisegment Winkler foundations on the rectangular Mindlin plates. They divided the four sides into two groups, in which the two parallel edges were one group. A set of edges were simply supported and another group was the combinations of uniform and classical boundary conditions. Younesian et al. studied strongly nonlinear generalized duffing oscillators [5] by using He's frequency-amplitude formulation and He's energy balance method and then proposed a closed form expression for the dynamic response of an elastic plate rested on a nonlinear elastic Winkler foundation [6]. Ansari et al. investigated 
the forced vibration of microbeam structures supported by nonlinear viscoelastic-type foundation [7], Kelvin-Voight foundation [8], and Winkler and Pasternak foundations [9] based on the Galerkin approach and multiple time-scales method. There are many related researches on the Winkler foundation, and we can refer to the relevant refs. [10-12]. The calculated results of the Winkler-type foundation plate model are very different from the actual results. In some special conditions, especially, the results could not meet the requirements any more by using the Winkler foundation model.

With the deepening of the research, the two-parameter elastic foundation model is proposed. Two independent parameters are used to represent the compressive strength and shear strength of the soil, which can overcome the inherent defects of the Winkler foundation model and effectively eliminate the discontinuity. In the two-parameter model, the Pasternak foundation is widely used. Nedri et al. [13] studied the free vibration analysis of simply supported thick laminated rectangular composite plates resting on elastic Pasternak-type foundations based on refined hyperbolic shear deformation theory. Baltacioğlu et al. [14] used the discrete singular convolution method to realize nonlinear static analysis of a thick laminated rectangular composite plate on nonlinear foundation by using the FSDT. Singh et al. [15] dealt with the postbuckling shear deformation of the laminated composite plates on the Pasternak-type foundation on the basis of HSDT and random system properties. It is the first time that a perturbation technique has been successfully combined with direct iterative technique by neglecting the changes in nonlinear stiffness matrix due to random variation of transverse displacements during iteration. Malekzadeh et al. [16] investigated the effect of nonideal simple supports and initial stresses on the vibration of laminated rectangular plates on Pasternak foundation based on the LindstedtPoincare perturbation technique. Kutlu et al. [17] derived a mixed-type finite element formulation to study the dynamic response of the Mindlin plate-arbitrarily orthotropic Pasternak foundation interaction by applying the Gâteaux differential. Tornabene et al. [18] considered the static and dynamic analyses of laminated doubly curved and degenerate shells and panels on the Winkler and Pasternak foundations by using the generalized differential quadrature (GDQ) method and FSDT. Jahromi et al. [19] studied free vibration of moderately thick rectangular plate partially resting on Pasternak foundation based on GDQ and FSDT. The boundary conditions of plate were considered as combinations of free, simple, or clamped support. Li and Zhang [20] investigated free vibration analysis of magnetoelectroelastic plate resting on a Pasternak-type foundation based on Mindlin plate theory. Khalili et al. [21] used the Lindstedt-Poincare perturbation technique to study the buckling of nonideal rectangular laminated plate on Pasternak foundation. One edge of the plate was allowed a small nonzero deflection and movement. Dehghany and Farajpour [22] dealt with exact solution for free vibration analysis of simply supported rectangular plates on Pasternak foundation on the basis of three-dimensional elasticity theory. Briscoe et al. [23] presented a solution for the buckling strength of simply supported plates on the Pasternak-type foundation under inplane bending loads by using the minimum potential energy principle. Thai et al. [24] proposed a simple refined theory for studying bending, buckling, and vibration of thick plates resting on Pasternak foundation. The boundary conditions of rectangular plates were expressed as two opposite edges with simply supported plates and the other two edges with arbitrary boundary conditions. Idowu et al. [25] proposed a fourth-order partial differential equation to study the dynamic effects of viscous damping on isotropic rectangular plates resting on Pasternak foundation subjected to moving loads. Bahmyari and Khedmati [26] used shear deformable plate theory and Element-Free Galerkin Method to study the free vibration analysis of nonhomogeneous moderately thick plates with point supports resting on Pasternak elastic foundation. Kiani et al. [27] considered instability of simply supported sandwich plates with functionally graded material (FGM) face sheets resting on the Pasternak foundations based on FSDT. There have been a lot of literatures of the plate resting on the Pasternak-type foundation. We can also check the relevant references, such as [28, 29]. However, these literatures have great limitations for the moderately thick or thick laminated rectangular plates resting on the elastic foundation which have arbitrary and special boundary conditions. It is necessary to study the effects of boundary conditions on the free and forced vibration characteristics of plate resting on the elastic foundation.

Stimulated by the restriction of the plate boundary conditions in the existing researches, the free and forced vibration characteristics of the moderately thick laminated rectangular plates are analyzed which rest on the Winkler or Pasternak foundations and have various uniform supported and multipoints supported boundary conditions. It should be pointed out that the free vibration analysis of the moderately thick laminated composite rectangular plate with nonuniform boundary conditions [30] has been done previously. However, it only discussed the free vibration analysis of the laminated plate with partial supports and multipoints supports. In this proposition, the free and forced vibration analyses of uniform and multipoints supported laminated rectangular plate resting on the Winkler and Pasternak foundations are studied in this paper. As we all know, there are many structural forms of plate in engineering applications, like stiffened plates [31-34], cracked rectangular plates [35-38], corroded plates [39-43], and so on. As the most common basic model, the rectangular plate structure is widely studied. An IFSM is extended to study the free and forced vibration of rectangular plates on the elastic Winkler-type and Pasternak-type foundation. This method is previously studied by Zhang and Li [44, 45]. According to the FSDT, the five displacement functions can be written as feasible period superposition functions. Their specific expressions are a double Fourier cosine series and two supplementary functions by ignoring the influence of boundary conditions. On the basis of the traditional Fourier series, these supplementary functions are added to eliminate the discontinuous or jumping phenomenon in the boundaries which are regarded as a periodic function and defined within the entire coordinates of laminate plate. These unknown 


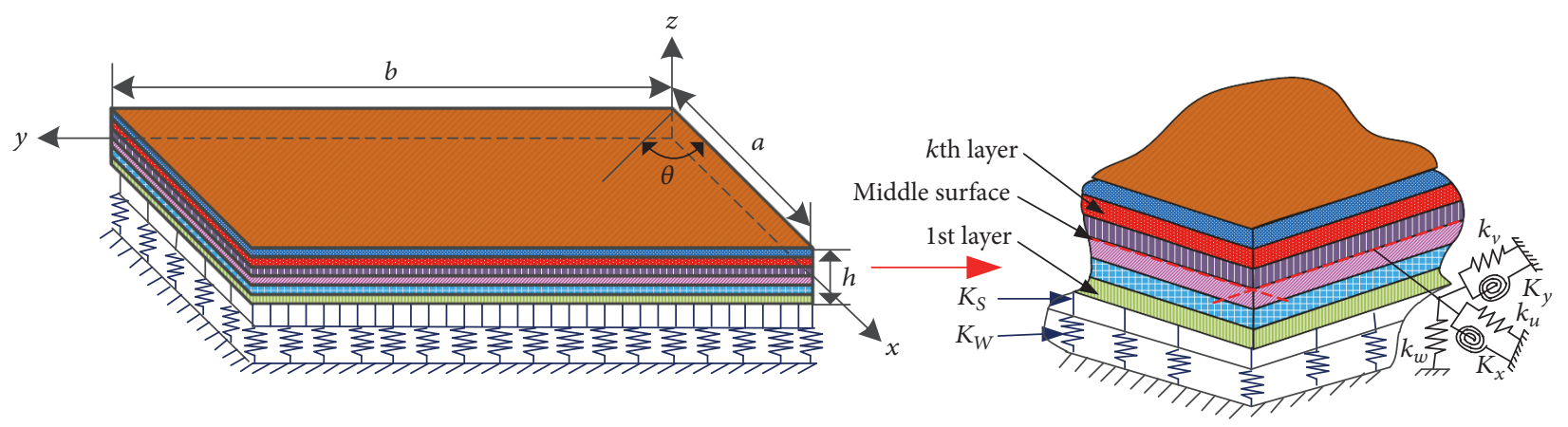

FIGURE 1: Rectangular plate resting on elastic foundations.

coefficients are defined in the generalized coordinates which can be solved by Rayleigh-Ritz procedure. It is very easy to realize the change of different boundary conditions by changing the stiffness value of the five springs on the four edges. The results obtained by this method are compared with those results obtained by literatures and FEM, which show good agreement. The work mainly deals with the consequences of the practical and significant constraints such as various uniform supports, multipoints supports, and various values of the foundation parameters.

\section{Theoretical Analysis}

A combination technique is used to get the vibration characteristics of orthotropic laminated plate structure based on artificial spring technique and Rayleigh-Ritz method. This plate under uniform supports or multipoints supports is rested on elastic Winkler-type and Pasternak-type foundation.

2.1. Establishment of the Model. As shown in Figure 1, a laminated rectangular plate model is established to analyze vibration characteristics. For the plate, the length, width, and thickness are $a, b$, and $h$. Establish a coordinate system in the plate mid-surface. In this coordinate system, the $x, y$, and $z$ represent the length, width, and thickness directions of the studied plate. Symbol $\theta$ is the laying angle between the layer fiber direction and the $x$-axis. For the sake of brevity, it is supposed that every lamina has the same material properties and thickness. For the elastic foundation, $K_{w}$ and $K_{s}$ are defined as linear Winkler foundation and linear Pasternak foundation parameters. Five types of spring are used to describe the boundary conditions of laminated foundation plate, which are linear springs $\left(k_{u}, k_{v}\right.$, and $\left.k_{w}\right)$ and rotational springs $\left(K_{x}, K_{y}\right)$, respectively. The arbitrary boundary conditions can be realized by setting the stiffness values of the five different springs [46-50]. For instance, the free boundary condition can be easily gained when the spring stiffness values on the four edges are zero. All the stiffness values are set to a large value to achieve the clamped boundary conditions in the numerical calculation.
2.2. Relationship between Kinematics and Stress. According to the displacements and rotations of the middle surface for the established plate model, the displacements can be expressed based on FSDT [51-53].

$$
\begin{aligned}
U(x, y, z, t) & =u(x, y, z, t)+z \phi_{x}(x, y, t), \\
V(x, y, z, t) & =v(x, y, z, t)+z \phi_{y}(x, y, t), \\
W(x, y, z, t) & =w(x, y, z, t),
\end{aligned}
$$

where $u, v$, and $w$ represent the middle surface displacements of the plate in the $x, y$, and $z$ directions and $\phi_{x}$ and $\phi_{y}$ are the rotations of transverse normal for $x$ - and $y$-axes, respectively. Then $t$ is the time variable.

For rectangular laminated plates, the linear strainsdisplacement relations of $k^{\prime}$ th layer can be got according to the strain-stress relationship of elasticity theory

$$
\begin{aligned}
& \varepsilon_{x x}=\varepsilon_{x x}^{0}+z_{k} \chi_{x x}, \\
& \varepsilon_{y y}=\varepsilon_{y y}^{0}+z_{k} \chi_{y y}, \\
& \gamma_{y z}=\gamma_{y z}^{0}, \\
& \gamma_{x z}=\gamma_{x z}^{0}, \\
& \gamma_{x y}=\gamma_{x y}^{0}+z_{k} \chi_{x y} .
\end{aligned}
$$

According to the above formulas, $\varepsilon_{x x}^{0}, \varepsilon_{y y}^{0}$, and $\gamma_{x y}^{0}$ express the normal and shear strains in the $o-x y z$ coordinate system. The symbols of transverse shear strains are marked as $\gamma_{x z}$ and $\gamma_{y z}$ which can be regarded as constant and ignore the thickness change. $\chi_{x x}, \chi_{y y}$, and $\chi_{x y}$ represent the corresponding curvature and twist changes. Besides, $z_{k}$ expresses the thickness variable range of $k$ 'th layer. Expressions for strain 
and generalized displacement relations can be established as

$$
\begin{aligned}
& \varepsilon_{x x}^{0}=\frac{\partial u}{\partial x}, \\
& \gamma_{x z}^{0}=\frac{\partial w}{\partial x}+\phi_{x}, \\
& \chi_{x x}=\frac{\partial \phi_{x}}{\partial x}, \\
& \varepsilon_{y y}^{0}=\frac{\partial v}{\partial y}, \\
& \gamma_{y z}^{0}=\frac{\partial w}{\partial y}+\phi_{y} \\
& \chi_{y y}=\frac{\partial \phi_{y}}{\partial y}, \\
& \gamma_{x y}^{0}=\frac{\partial u}{\partial y}+\frac{\partial v}{\partial x} \\
& \chi_{x y}=\frac{\partial \phi_{x}}{\partial y}+\frac{\partial \phi_{y}}{\partial x} .
\end{aligned}
$$

According to the generalized Hooke's law, the relation between stress and strain can be expressed as

$$
\left\{\begin{array}{c}
\sigma_{x x} \\
\sigma_{y y} \\
\tau_{x y} \\
\tau_{y z} \\
\tau_{x z}
\end{array}\right\}=\left[\begin{array}{ccccc}
\overline{Q_{11}^{k}} & \overline{Q_{12}^{k}} & \overline{Q_{16}^{k}} & 0 & 0 \\
\overline{Q_{12}^{k}} & \overline{Q_{22}^{k}} & \overline{Q_{26}^{k}} & 0 & 0 \\
\overline{Q_{16}^{k}} & \overline{Q_{26}^{k}} & \overline{Q_{66}^{k}} & 0 & 0 \\
0 & 0 & 0 & \overline{Q_{44}^{k}} & \overline{Q_{45}^{k}} \\
0 & 0 & 0 & \overline{Q_{45}^{k}} & \frac{Q_{55}^{k}}{\gamma_{y z}}
\end{array}\right]\left[\begin{array}{c}
\varepsilon_{x x} \\
\varepsilon_{y y} \\
\gamma_{x y} \\
\gamma_{x z}
\end{array}\right]
$$

in which $\sigma_{x x}$ and $\sigma_{y y}$ are the normal stresses and $\tau_{y z}, \tau_{x z}$, and $\tau_{x y}$ are shear stresses in the $o-x y z$ coordinate system. Besides, the specific expression of $k$ 'th layered stiffness coefficients $\overline{Q_{p l}^{k}}(p, l=1,2,4,5,6)[54,55]$ can be written as

$$
\begin{aligned}
\overline{Q_{11}^{k}}= & Q_{11}^{k} \cos ^{4} \theta^{k}+2\left(Q_{12}^{k}+2 Q_{66}^{k}\right) \cos ^{2} \theta^{k} \sin ^{2} \theta^{k} \\
& +Q_{22}^{k} \sin ^{4} \theta^{k}, \\
\overline{Q_{12}^{k}}= & \left(Q_{11}^{k}+Q_{22}^{k}-4 Q_{66}^{k}\right) \cos ^{2} \theta^{k} \sin ^{2} \theta^{k} \\
& +Q_{12}^{k}\left(\sin ^{4} \theta^{k}+\cos ^{4} \theta^{k}\right), \\
\overline{Q_{22}^{k}}= & Q_{11}^{k} \sin ^{4} \theta^{k}+2\left(Q_{12}^{k}+2 Q_{66}^{k}\right) \cos ^{2} \theta^{k} \sin ^{2} \theta^{k} \\
& +Q_{22}^{k} \cos ^{4} \theta^{k}, \\
\overline{Q_{16}^{k}}= & \left(Q_{11}^{k}-Q_{12}^{k}-2 Q_{66}^{k}\right) \cos ^{3} \theta^{k} \sin ^{k} \\
& +\left(Q_{12}^{k}-Q_{22}^{k}+2 Q_{66}^{k}\right) \cos \theta^{k} \sin ^{3} \theta^{k},
\end{aligned}
$$

$$
\begin{aligned}
\overline{Q_{26}^{k}}= & \left(Q_{11}^{k}-Q_{12}^{k}-2 Q_{66}^{k}\right) \cos \theta^{k} \sin ^{3} \theta^{k} \\
& +\left(Q_{12}^{k}-Q_{22}^{k}+2 Q_{66}^{k}\right) \cos ^{3} \theta^{k} \sin \theta^{k}, \\
\overline{Q_{66}^{k}}= & \left(Q_{11}^{k}+Q_{22}^{k}-2 Q_{12}^{k}-2 Q_{66}^{k}\right) \cos ^{2} \theta^{k} \sin ^{2} \theta^{k} \\
& +Q_{66}^{k}\left(\sin ^{4} \theta^{k}+\cos ^{4} \theta^{k}\right), \\
\overline{Q_{44}^{k}}= & Q_{44}^{k} \cos ^{2} \theta^{k}+Q_{55}^{k} \sin ^{2} \theta^{k}, \\
\overline{Q_{45}^{k}}= & \left(Q_{55}^{k}-Q_{44}^{k}\right) \cos \theta^{k} \sin \theta^{k}, \\
\overline{Q_{55}^{k}}= & Q_{55}^{k} \cos ^{2} \theta^{k}+Q_{44}^{k} \sin ^{2} \theta^{k},
\end{aligned}
$$

where $\theta$ is the laying angle and $Q_{p l}^{k}$ represents the material coefficients of the $k$ 'th layer which can be obtained by building the relationships with longitudinal modulus $E_{1}^{k}$, the transverse modulus $E_{2}^{k}$, Poisson's ratios $\mu_{12}^{k}$ and $\mu_{21}^{k}$, and shear moduli $G_{12}^{k}, G_{13}^{k}$, and $G_{23}^{k}$.

$$
\begin{aligned}
& Q_{11}^{k}=\frac{E_{1}^{k}}{1-\mu_{12}^{k} \mu_{21}^{k}}, \\
& Q_{12}^{k}=\mu_{21}^{k} Q_{11}^{k}, \\
& Q_{22}^{k}=\frac{E_{2}^{k}}{1-\mu_{12}^{k} \mu_{21}^{k}}, \\
& Q_{44}^{k}=G_{23}^{k}, \\
& Q_{55}^{k}=G_{13}^{k}, \\
& Q_{66}^{k}=G_{12}^{k} .
\end{aligned}
$$

In order to seek simplicity, the material constants of each layer are the same, which can be expressed as $E_{i}^{k}=E_{i}, G_{12}^{k}=$ $G_{i, j}$, and $\mu_{i, j}^{k}=\mu_{i, j}(i, j=1,2,3)$. In addition, the relationship of $\mu_{12}$ and $\mu_{21}$ is $\mu_{12} E_{2}=\mu_{21} E_{1}$. It should be pointed out that the isotropic plate resting on the elastic foundations can be easily analyzed by letting $E_{1}=E_{2}, G_{12}=G_{13}=G_{23}=$ $E_{1} /\left(2+2 \mu_{12}\right)$. By introducing the shear correction factor $\kappa$, the relation between the generalized forces and strains can be finally obtained $[51,52]$. The specific expressions are shown as follows:

$$
\begin{aligned}
& {\left[\begin{array}{c}
N_{x} \\
N_{y} \\
N_{x y} \\
M_{x} \\
M_{y} \\
M_{x y}
\end{array}\right]=\left[\begin{array}{llllll}
A_{11} & A_{12} & A_{16} & B_{11} & B_{12} & B_{16} \\
A_{12} & A_{22} & A_{26} & B_{12} & B_{22} & B_{26} \\
A_{16} & A_{26} & A_{66} & B_{16} & B_{26} & B_{66} \\
B_{11} & B_{12} & B_{16} & D_{11} & D_{12} & D_{16} \\
B_{12} & B_{22} & B_{26} & D_{12} & D_{22} & D_{26} \\
B_{16} & B_{26} & B_{66} & D_{16} & D_{26} & D_{66}
\end{array}\right]\left[\begin{array}{c}
\varepsilon_{x x}^{0} \\
\varepsilon_{y y}^{0} \\
\gamma_{x y}^{0} \\
\chi_{x x} \\
\chi_{y y} \\
\chi_{x y}
\end{array}\right],} \\
& {\left[\begin{array}{l}
Q_{x} \\
Q_{y}
\end{array}\right]=\kappa\left[\begin{array}{lll}
A_{55} & A_{45} \\
A_{45} & A_{55}
\end{array}\right]\left[\begin{array}{l}
\gamma_{x z} \\
\gamma_{y z}
\end{array}\right]}
\end{aligned}
$$


in which the generalized forces include normal forces $\left(N_{x}\right.$, $\left.N_{y}\right)$, shear force $\left(N_{x y}\right)$, bending moments $\left(M_{x}, M_{y}\right)$, twisting moment $\left(M_{x y}\right)$, and transverse shear forces $\left(Q_{x}, Q_{y}\right)$. In addition, $A_{i j}, B_{i j}$, and $D_{i j}$ are extensional, extensional-bending, and bending stiffness coefficients, whose expressions are written as

$$
\begin{aligned}
& A_{i j}=\sum_{k=1}^{N} \overline{Q_{i j}^{k}}\left(Z_{k+1}-Z_{k}\right), \\
& B_{i j}=\frac{1}{2} \sum_{k=1}^{N} \overline{Q_{i j}^{k}}\left(Z_{k+1}^{2}-Z_{k}^{2}\right), \\
& D_{i j}=\frac{1}{3} \sum_{k=1}^{N} \overline{Q_{i j}^{k}}\left(Z_{k+1}^{3}-Z_{k}^{3}\right)
\end{aligned}
$$

in which $N$ donates the total number of layers. Moreover, when we study the vibration characteristics of the isotropic plate, the extensional-bending stiffness coefficients $B_{i j}$ are zero and $A_{i j}$ and $D_{i j}$ are independent.

2.3. Energy Equation. The main work of this paper is to investigate the vibration characteristics of the moderately thick laminated composite rectangular plate with uniform and multipoints supports which is rested on the elastic foundations. Rayleigh-Ritz energy method is extended to study the free and forced vibration of plate on the Winkler and Pasternak foundations. The Lagrangian energy function for the laminated plate can be written as

$$
L_{P}=T_{P}-U_{P}-U_{f}-V_{\text {springs }}-W_{\text {ext }} .
$$

$T_{P}$ expresses the total kinetic energy of laminated plate whose expression is

$$
\begin{aligned}
T_{p} & =\frac{1}{2} \int_{0}^{a} \int_{0}^{b}\left[I_{0}\left(\frac{\partial u}{\partial t}\right)^{2}+I_{0}\left(\frac{\partial v}{\partial t}\right)^{2}+I_{0}\left(\frac{\partial w}{\partial t}\right)^{2}\right. \\
& +I_{2}\left(\frac{\partial \phi_{x}}{\partial t}\right)^{2}+I_{2}\left(\frac{\partial \phi_{y}}{\partial t}\right)^{2}+2 I_{1}\left(\frac{\partial u}{\partial t}\right)\left(\frac{\partial \phi_{x}}{\partial t}\right) \\
& \left.+2 I_{1}\left(\frac{\partial v}{\partial t}\right)\left(\frac{\partial \phi_{y}}{\partial t}\right)\right] d y d x, \\
I_{0} & =\sum_{k=1}^{N} \int_{Z_{k}}^{Z_{k+1}} \rho^{k} d z, \\
I_{1} & =\sum_{k=1}^{N} \int_{Z_{k}}^{Z_{k+1}} \rho^{k} z d z, \\
I_{2} & =\sum_{k=1}^{N} \int_{Z_{k}}^{Z_{k+1}} \rho^{k} z^{2} d z
\end{aligned}
$$

in which $I_{0}, I_{1}$, and $I_{2}$ are the inertia terms of the plate, and $\rho^{k}$ is area density of the $k^{\prime}$ th layer.
$U_{P}$ expresses the strain energy for the moderately thick plates:

$$
\begin{aligned}
U_{P} & =\frac{1}{2} \int_{0}^{a} \int_{0}^{b}\left\{N_{x} \varepsilon_{x x}^{0}+N_{y} \varepsilon_{y y}^{0}+N_{x y} \varepsilon_{x y}^{0}+M_{x} \chi_{x x}\right. \\
& \left.+M_{y} \chi_{y y}+M_{x y} \chi_{x y}+Q_{x} \gamma_{x z}+Q_{y} \gamma_{y z}\right\} d x d y .
\end{aligned}
$$

Substituting (3), (7), and (8) into (11) can obtain the relations between strain energy and displacements in midsurface of plate. Then, strain energy expression can be written as a superposition of three components, which are stretching energy $\left(U_{S}\right)$, bending energy $\left(U_{B}\right)$, and bending-stretching coupling energy $\left(U_{B S}\right)$.

$$
\begin{aligned}
& U_{S}=\frac{1}{2} \int_{0}^{a} \int_{0}^{b}\left\{A_{11}\left(\frac{\partial u}{\partial x}\right)^{2}+A_{22}\left(\frac{\partial v}{\partial y}\right)^{2}\right. \\
& +2 A_{12}\left(\frac{\partial u}{\partial x}\right)\left(\frac{\partial v}{\partial y}\right)+A_{66}\left(\frac{\partial u}{\partial y}+\frac{\partial v}{\partial x}\right)^{2} \\
& +2 A_{16}\left(\frac{\partial u}{\partial y}+\frac{\partial v}{\partial x}\right)\left(\frac{\partial u}{\partial x}\right)+2 A_{26}\left(\frac{\partial u}{\partial y}+\frac{\partial v}{\partial x}\right) \\
& \cdot\left(\frac{\partial v}{\partial y}\right)+\kappa_{c} A_{44}\left(\frac{\partial w}{\partial y}+\phi_{y}\right)^{2} \\
& +\kappa_{c} A_{55}\left(\frac{\partial w}{\partial x}+\phi_{x}\right)^{2}+2 \kappa_{c} A_{45}\left(\frac{\partial w}{\partial x}+\phi_{x}\right) \\
& \left.\cdot\left(\frac{\partial w}{\partial y}+\phi_{y}\right)\right\} d x d y \\
& U_{B}=\frac{1}{2} \int_{0}^{a} \int_{0}^{b}\left\{D_{11}\left(\frac{\partial \phi_{x}}{\partial x}\right)^{2}+D_{22}\left(\frac{\partial \phi_{y}}{\partial y}\right)^{2}\right. \\
& +2 D_{12}\left(\frac{\partial \phi_{x}}{\partial x}\right)\left(\frac{\partial \phi_{y}}{\partial y}\right)+D_{66}\left(\frac{\partial \phi_{x}}{\partial y}+\frac{\partial \phi_{y}}{\partial x}\right)^{2} \\
& +2 D_{16}\left(\frac{\partial \phi_{x}}{\partial y}+\frac{\partial \phi_{y}}{\partial x}\right)\left(\frac{\partial \phi_{x}}{\partial x}\right) \\
& \left.+2 D_{26}\left(\frac{\partial \phi_{x}}{\partial y}+\frac{\partial \phi_{y}}{\partial x}\right)\left(\frac{\partial \phi_{y}}{\partial y}\right)\right\} d x d y, \\
& U_{B S}=\int_{0}^{a} \int_{0}^{b}\left\{B_{11}\left(\frac{\partial u}{\partial x}\right)\left(\frac{\partial \phi_{x}}{\partial x}\right)\right. \\
& +B_{12}\left[\left(\frac{\partial u}{\partial x}\right)\left(\frac{\partial \phi_{y}}{\partial y}\right)+\left(\frac{\partial v}{\partial y}\right)\left(\frac{\partial \phi_{x}}{\partial x}\right)\right] \\
& +B_{22}\left(\frac{\partial v}{\partial y}\right)\left(\frac{\partial \phi_{y}}{\partial y}\right)+B_{66}\left(\frac{\partial v}{\partial x}+\frac{\partial u}{\partial y}\right) \\
& \cdot\left(\frac{\partial \phi_{x}}{\partial y}+\frac{\partial \phi_{y}}{\partial x}\right)+\left[B_{16}\left(\frac{\partial u}{\partial x}\right)+B_{26}\left(\frac{\partial v}{\partial y}\right)\right]
\end{aligned}
$$




$$
\begin{aligned}
& \cdot\left(\frac{\partial \phi_{x}}{\partial y}+\frac{\partial \phi_{y}}{\partial x}\right)+\left[B_{16}\left(\frac{\partial \phi_{x}}{\partial x}\right)+B_{26}\left(\frac{\partial \phi_{y}}{\partial y}\right)\right] \\
& \left.\cdot\left(\frac{\partial v}{\partial x}+\frac{\partial u}{\partial y}\right)\right\} d x d y .
\end{aligned}
$$

The strain energy due to the Winkler and Pasternak foundations is given by

$$
\begin{aligned}
U_{f} & =\frac{1}{2} \int_{0}^{a} \int_{0}^{b}\left\{K_{W} w^{2}\right. \\
& \left.+K_{S}\left[\left(\frac{\partial w}{\partial x}\right)^{2}+\left(\frac{\partial w}{\partial y}\right)^{2}\right]\right\} d x d y .
\end{aligned}
$$

For the elastic Winkler foundation, we just need to set the Pasternak foundation parameter $K_{S}$ to zero. Then, the influence of the free vibration for the plate which is on the Winkler-type elastic foundation can be studied with the change of the Winkler foundation parameter $K_{W}$. In this paper, the main interests are studying the special boundary constraints and variation of Winkler and Pasternak foundations by introducing artificial virtual spring technology, which can be found in [56-58]. So the cases of uniform supported and multipoints supported boundary conditions whose plates are rested on the Winkler and Pasternak foundations will be considered here.

$V_{\text {springs }}^{\text {uniform }}$ is the potential energy on the four edges of the plate with elastic uniform boundary conditions. It is simulated with five kinds of springs evenly distributed on four edges.

$$
\begin{aligned}
& V_{\text {springs }}^{\text {uniform }}=\frac{1}{2} \int_{0}^{b} \int_{-h / 2}^{h / 2}\left\{\left[k_{x 0}^{u} u(x, y)^{2}+k_{x 0}^{v} v(x, y)^{2}+k_{x 0}^{w} w(x, y)^{2}+K_{x 0}^{x} \phi_{x}(x, y)^{2}+K_{x 0}^{y} \phi_{y}(x, y)^{2}\right]_{x=0}\right. \\
& \left.+\left[k_{x a}^{u} u(x, y)^{2}+k_{x a}^{v} v(x, y)^{2}+k_{x a}^{w} w(x, y)^{2}+K_{x a}^{x} \phi_{x}(x, y)^{2}+K_{x a}^{y} \phi_{y}(x, y)^{2}\right]_{x=a}\right\} d z d y+\frac{1}{2} \\
& \quad \int_{0}^{a} \int_{-h / 2}^{h / 2}\left\{\left[k_{y 0}^{u} u(x, y)^{2}+k_{y 0}^{v} v(x, y)^{2}+k_{y 0}^{w} w(x, y)^{2}+K_{y 0}^{x} \phi_{x}(x, y)^{2}+K_{y 0}^{y} \phi_{y}(x, y)^{2}\right]_{y=0}\right. \\
& \left.+\left[k_{y b}^{u} u(x, y)^{2}+k_{y b}^{v} v(x, y)^{2}+k_{y b}^{w} w(x, y)^{2}+K_{y b}^{x} \phi_{x}(x, y)^{2}+K_{y b}^{y} \phi_{y}(x, y)^{2}\right]_{y=b}\right\} d z d x .
\end{aligned}
$$

For the cases of multipoints supports, the supported points are evenly distributed on the four edges. For intuitive understanding, Figure 2 gives the distributions of 4 -point, 8 -point, and 16-point supported boundary conditions. They can be regarded as the discretization of uniform support. Therefore, the potential energy $V_{\text {springs }}^{\text {points }}$ for the plate with multipoints supports can be written as

$$
\begin{aligned}
V_{\text {springs }}^{\text {points }}=\frac{1}{2} & \sum_{r=0}^{N R}\left[k_{x 0}^{u} u\left(x_{r}, y_{r}\right)^{2}+k_{x 0}^{v} v\left(x_{r}, y_{r}\right)^{2}+k_{x 0}^{w} w\left(x_{r}, y_{r}\right)^{2}+K_{x 0}^{x} \phi_{x}\left(x_{r}, y_{r}\right)^{2}+K_{x 0}^{y} \phi_{y}\left(x_{r}, y_{r}\right)^{2}\right] x_{x_{r}=0}+\frac{1}{2} \\
& \cdot \sum_{r=0}^{N R}\left[k_{x a}^{u} u\left(x_{r}, y_{r}\right)^{2}+k_{x a}^{v} v\left(x_{r}, y_{r}\right)^{2}+k_{x a}^{w} w\left(x_{r}, y_{r}\right)^{2}+K_{x a}^{x} \phi_{x}\left(x_{r}, y_{r}\right)^{2}+K_{x a}^{y} \phi_{y}\left(x_{r}, y_{r}\right)^{2}\right]+\frac{1}{2} x_{r}=a \\
& \cdot \sum_{s=0}^{N S}\left[k_{y 0}^{u} u\left(x_{s}, y_{s}\right)^{2}+k_{y 0}^{v} v\left(x_{s}, y_{s}\right)^{2}+k_{y 0}^{w} w\left(x_{s}, y_{s}\right)^{2}+K_{y 0}^{x} \phi_{x}\left(x_{s}, y_{s}\right)^{2}+K_{y 0}^{y} \phi_{y}\left(x_{s}, y_{s}\right)^{2}\right]+\frac{1}{2}+y_{s}=0 \\
& \cdot \sum_{s=0}^{N S}\left[k_{y b}^{u} u\left(x_{s}, y_{s}\right)^{2}+k_{y b}^{v} v\left(x_{s}, y_{s}\right)^{2}+k_{y b}^{w} w\left(x_{s}, y_{s}\right)^{2}+K_{y b}^{x} \phi_{x}\left(x_{s}, y_{s}\right)^{2}+K_{y b}^{y} \phi_{y}\left(x_{s}, y_{s}\right)^{2}\right]
\end{aligned}
$$




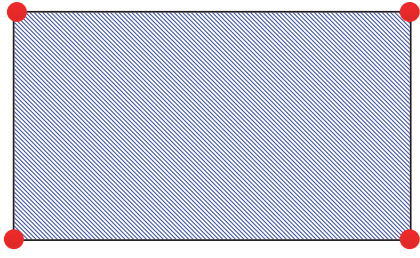

(a) 4-point support

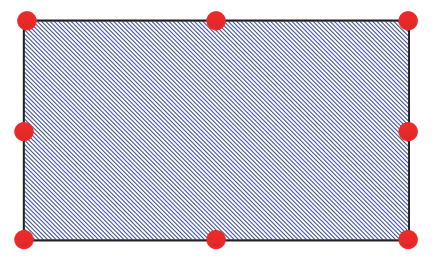

(b) 8-point support

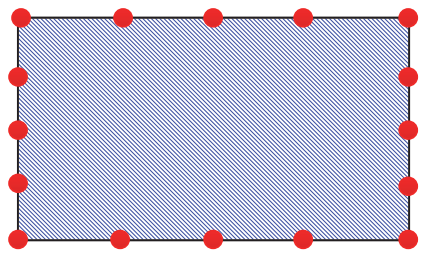

(c) 16-point support

FIGURE 2: Laminated plate with various multipoints supported boundary conditions.

$W_{\text {ext }}$ expresses the work done by the external excitation force on the moderately thick plates:

$$
\begin{aligned}
& W_{\text {ext }} \\
& \quad=\iint_{S}\left(f_{u} u+f_{v} v+f_{w} w+f_{\phi_{x}} \phi_{x}+f_{\phi_{y}} \phi_{y}\right) d x d y,
\end{aligned}
$$

where $f_{i}\left(i=u, v, w, \phi_{x}, \phi_{y}\right)$ is the external load distribution function on the plate. In this paper, the normal harmonic point force $F_{i}$ on the plate is applied to study the flexural vibration behavior of the composite plate. Therefore, the load distribution function $f_{i}$ can be expressed as

$$
f_{i}=F_{i} \delta\left(x-x_{e}\right) \delta\left(y-y_{e}\right)
$$

where $\left(x_{e}, y_{e}\right)$ is the position of point force. $\delta$ is the 2D Dirac function.

2.4. Kinematics Balance Equation. The kinematics balance equations for the moderately thick plate can be obtained by Hamilton's principle [51, 52].

$$
\begin{aligned}
\frac{\partial N_{x}}{\partial x}+\frac{\partial N_{x y}}{\partial y} & =I_{0} \frac{\partial^{2} u}{\partial t^{2}}+I_{1} \frac{\partial^{2} \phi_{x}}{\partial t^{2}}, \\
\frac{\partial N_{x y}}{\partial x}+\frac{\partial N_{y}}{\partial y} & =I_{0} \frac{\partial^{2} v}{\partial t^{2}}+I_{1} \frac{\partial^{2} \phi_{y}}{\partial t^{2}}, \\
\frac{\partial M_{x}}{\partial x}+\frac{\partial M_{x y}}{\partial y}-Q_{x} & =I_{1} \frac{\partial^{2} u}{\partial t^{2}}+I_{2} \frac{\partial^{2} \phi_{x}}{\partial t^{2}}, \\
\frac{\partial Q_{x}}{\partial x}+\frac{\partial Q_{y}}{\partial y} & =I_{0} \frac{\partial^{2} w}{\partial t^{2}}, \\
\frac{\partial M_{x y}}{\partial x}+\frac{\partial M_{y}}{\partial y}-Q_{y} & =I_{1} \frac{\partial^{2} v}{\partial t^{2}}+I_{2} \frac{\partial^{2} \phi_{y}}{\partial t^{2}} .
\end{aligned}
$$

As we can see from (18), the displacement functions required second-order derivatives. The kinematics balance equations can be rewritten as a matrix form by combining (3), (7), and (18) simultaneously.

$$
\begin{aligned}
& \left\{\left[\begin{array}{ccccc}
L_{11} & L_{12} & 0 & L_{14} & L_{15} \\
L_{12} & L_{22} & 0 & L_{24} & L_{25} \\
0 & 0 & L_{33} & L_{34} & L_{35} \\
L_{14} & L_{24} & L_{34} & L_{44} & L_{45} \\
L_{15} & L_{25} & L_{35} & L_{45} & L_{55}
\end{array}\right]\right. \\
& \left.-\left[\begin{array}{ccccc}
M_{11} & 0 & 0 & M_{14} & 0 \\
0 & M_{22} & 0 & 0 & M_{25} \\
0 & 0 & M_{33} & 0 & 0 \\
M_{14} & 0 & 0 & M_{44} & 0 \\
0 & M_{25} & 0 & 0 & M_{55}
\end{array}\right]\right\}\left[\begin{array}{c}
u \\
v \\
w \\
\phi_{x} \\
\phi_{y}
\end{array}\right]
\end{aligned}
$$

$$
=\left[\begin{array}{c}
F_{u} \\
F_{v} \\
F_{w} \\
F_{\phi_{x}} \\
F_{\phi_{y}}
\end{array}\right],
$$

where linear differential operators are expressed as $L_{i j}$ and $M_{i j}$. The specific expressions are given below:

$$
\begin{aligned}
& L_{11}=A_{11} \frac{\partial^{2}}{\partial x^{2}}+2 A_{16} \frac{\partial^{2}}{\partial x \partial y}+A_{66} \frac{\partial^{2}}{\partial y^{2}}, \\
& L_{12}=A_{16} \frac{\partial^{2}}{\partial x^{2}}+\left(A_{12}+A_{66}\right) \frac{\partial^{2}}{\partial x \partial y}+A_{26} \frac{\partial^{2}}{\partial y^{2}}, \\
& L_{14}=B_{11} \frac{\partial^{2}}{\partial x^{2}}+2 B_{16} \frac{\partial^{2}}{\partial x \partial y}+B_{66} \frac{\partial^{2}}{\partial y^{2}} \\
& L_{15}=B_{16} \frac{\partial^{2}}{\partial x^{2}}+\left(B_{12}+B_{66}\right) \frac{\partial^{2}}{\partial x \partial y}+B_{26} \frac{\partial^{2}}{\partial y^{2}} \\
& L_{22}=A_{66} \frac{\partial^{2}}{\partial x^{2}}+2 A_{26} \frac{\partial^{2}}{\partial x \partial y}+A_{22} \frac{\partial^{2}}{\partial y^{2}}
\end{aligned}
$$




$$
\begin{aligned}
L_{24}= & B_{16} \frac{\partial^{2}}{\partial x^{2}}+\left(B_{12}+B_{66}\right) \frac{\partial^{2}}{\partial x \partial y}+B_{26} \frac{\partial^{2}}{\partial y^{2}} \\
L_{25}= & B_{66} \frac{\partial^{2}}{\partial x^{2}}+2 B_{26} \frac{\partial^{2}}{\partial x \partial y}+B_{22} \frac{\partial^{2}}{\partial y^{2}}, \\
L_{33}= & -A_{55} \frac{\partial^{2}}{\partial x^{2}}-2 A_{45} \frac{\partial^{2}}{\partial x \partial y}-A_{44} \frac{\partial^{2}}{\partial y^{2}}, \\
L_{34}= & -A_{55} \frac{\partial}{\partial x}-A_{45} \frac{\partial}{\partial y}, \\
L_{44}= & D_{11} \frac{\partial^{2}}{\partial x^{2}}+2 D_{16} \frac{\partial^{2}}{\partial x \partial y}+D_{66} \frac{\partial^{2}}{\partial y^{2}}-A_{55}, \\
L_{35}= & -A_{45} \frac{\partial}{\partial x}-A_{44} \frac{\partial}{\partial y}, \\
L_{45}= & D_{16} \frac{\partial^{2}}{\partial x^{2}}+\left(D_{12}+D_{66}\right) \frac{\partial^{2}}{\partial x \partial y}+D_{26} \frac{\partial^{2}}{\partial y^{2}} \\
M_{14}= & M_{25}=-A_{15} \frac{\partial^{2}}{\partial t}, \\
L_{55}= & D_{66} \frac{\partial^{2}}{\partial x^{2}}+2 D_{26} \frac{\partial^{2}}{\partial x \partial y}+D_{22} \frac{\partial^{2}}{\partial y^{2}}-A_{44} \\
M_{33}=-I_{0} \frac{\partial^{2}}{\partial t}, & I_{2} \frac{\partial^{2}}{\partial t} \cdot
\end{aligned}
$$

2.5. Displacement Expression. An IFSM is applied to express the displacements of the moderately thick laminated rectangular plate on the elastic foundations. The expressions ignore the boundary conditions and eliminate the discontinuous or jumping phenomenon in the boundaries. They can be regarded as a periodic function which is defined within the entire coordinates [59]. The specific displacement expressions of the plate are given below:

$$
\begin{aligned}
{\left[\begin{array}{l}
u \\
v \\
w \\
\phi_{x} \\
\phi_{y}
\end{array}\right]=\left[\begin{array}{lllll}
\mathbf{P} & \mathbf{0} & \mathbf{0} & \mathbf{0} & \mathbf{0} \\
\mathbf{0} & \mathbf{P} & \mathbf{0} & \mathbf{0} & \mathbf{0} \\
\mathbf{0} & \mathbf{0} & \mathbf{P} & \mathbf{0} & \mathbf{0} \\
\mathbf{0} & \mathbf{0} & \mathbf{0} & \mathbf{P} & \mathbf{0} \\
\mathbf{0} & \mathbf{0} & \mathbf{0} & \mathbf{0} & \mathbf{P}
\end{array}\right]\left[\begin{array}{c}
\mathbf{A}_{m n} \\
\mathbf{B}_{m n} \\
\mathbf{C}_{m n} \\
\mathbf{D}_{m n} \\
\mathbf{E}_{m n}
\end{array}\right], } \\
\mathbf{P}=\left\{\cos \left(\lambda_{0} x\right) \cos \left(\lambda_{0} y\right), \ldots, \cos \left(\lambda_{0} x\right) \cos \left(\lambda_{n} y\right),\right. \\
\quad \ldots, \cos \left(\lambda_{m} x\right) \cos \left(\lambda_{n} y\right), \ldots, \cos \left(\lambda_{M} x\right) \cos \left(\lambda_{N} y\right), \\
\sin \left(\lambda_{-2} x\right) \cos \left(\lambda_{0} y\right), \ldots, \sin \left(\lambda_{-2} x\right) \cos \left(\lambda_{n} y\right), \ldots, \\
\sin \left(\lambda_{-2} x\right) \cos \left(\lambda_{N} y\right), \ldots, \sin \left(\lambda_{-1} x\right) \cos \left(\lambda_{N} y\right),
\end{aligned}
$$

$$
\begin{aligned}
& \cos \left(\lambda_{0} x\right) \sin \left(\lambda_{-2} y\right), \cos \left(\lambda_{0} x\right) \sin \left(\lambda_{-1} y\right), \ldots, \\
& \left.\cos \left(\lambda_{m} x\right) \sin \left(\lambda_{-2} y\right), \ldots, \cos \left(\lambda_{M} x\right) \sin \left(\lambda_{-1} y\right)\right\},
\end{aligned}
$$

$$
\begin{gathered}
\mathbf{A}_{m n}=\left\{A_{0,0}^{1}, \ldots, A_{0, n}^{1}, \ldots, A_{m, n}^{1}, \ldots, A_{M, N}^{1}, A_{-2,0}^{2}, \ldots,\right. \\
A_{-2, n}^{2}, \ldots, A_{-2, N}^{2}, \ldots, A_{-1, N}^{2}, A_{0,-2}^{3}, A_{0,-1}^{3}, \ldots, A_{m,-2}^{3}, \\
\left.\ldots, A_{M,-1}^{3}\right\}^{T} \\
\mathbf{B}_{m n}=\left\{B_{0,0}^{1}, \ldots, B_{0, n}^{1}, \ldots, B_{m, n}^{1}, \ldots, B_{M, N}^{1}, B_{-2,0}^{2}, \ldots, B_{-2, n}^{2},\right. \\
\quad \ldots, B_{-2, N}^{2}, \ldots, B_{-1, N}^{2}, B_{0,-2}^{3}, B_{0,-1}^{3}, \ldots, B_{m,-2}^{3}, \ldots, \\
\left.B_{M,-1}^{3}\right\}^{T}, \\
\mathbf{C}_{m n}=\left\{C_{0,0}^{1}, \ldots, C_{0, n}^{1}, \ldots, C_{m, n}^{1}, \ldots, C_{M, N}^{1}, C_{-2,0}^{2}, \ldots,\right. \\
C_{-2, n}^{2}, \ldots, C_{-2, N}^{2}, \ldots, C_{-1, N}^{2}, C_{0,-2}^{3}, C_{0,-1}^{3}, \ldots, C_{m,-2}^{3}, \ldots, \\
\left.C_{M,-1}^{3}\right\}^{T}, \\
\mathbf{D}_{m n}=\left\{D_{0,0}^{1}, \ldots, D_{0, n}^{1}, \ldots, D_{m, n}^{1}, \ldots, D_{M, N}^{1}, D_{-2,0}^{2}, \ldots,\right. \\
D_{-2, n}^{2}, \ldots, D_{-2, N}^{2}, \ldots, D_{-1, N}^{2}, D_{0,-2}^{3}, D_{0,-1}^{3}, \ldots, D_{m,-2}^{3}, \\
\left.\quad \ldots, D_{M,-1}^{3}\right\}^{T}, \\
\left.E_{M,-1}^{3}\right\}^{T}, \\
\mathbf{E}_{m n}=\left\{E_{0,0}^{1}, \ldots, E_{0, n}^{1}, \ldots, E_{m, n}^{1}, \ldots, E_{M, N}^{1}, E_{-2,0}^{2}, \ldots, E_{-2, n}^{2},\right. \\
\quad, E_{-2, N}^{2}, \ldots, E_{-1, N}^{2}, E_{0,-2}^{3}, E_{0,-1}^{3}, \ldots, E_{m,-2}^{3}, \ldots,
\end{gathered}
$$

where $\lambda_{m}=m \pi / a$ and $\lambda_{n}=n \pi / b$. Besides, $\mathbf{A}_{m n}, \mathbf{B}_{m n}, \mathbf{C}_{m n}$, $\mathbf{D}_{m n}$, and $\mathbf{E}_{m n}$ are $2 \mathrm{D}$ Fourier coefficients vector, which are composed by $A_{m n}^{i}, B_{m n}^{i}, C_{m n}^{i}, D_{m n}^{i}$, and $E_{m n}^{i}(i=1,2,3)$, respectively.

There have been a lot of references about the RayleighRitz technology, such as [60-62], and Ritz like methods, such as [63-65]. In this paper, based on the Rayleigh-Ritz technology, a set of linear algebraic equations directed against Fourier unknown coefficients on displacement equations can be got by combining (18)-(23e) simultaneously. A matrix form can be obtained by transformation

$$
\left(\mathbf{K}-\omega^{2} \mathbf{M}\right) \mathbf{G}=\overline{\mathbf{F}}
$$

When we study the free vibration of the plate, we only need to ignore the external force vector $\overline{\mathbf{F}}$. K, $\mathbf{M}$, and $\mathbf{G}$ are stiffness matrix, mass matrix, and unknown Fourier coefficients vector, separately. The specified expressions of $\mathbf{K}$, $\mathbf{M}$, and $\overline{\mathbf{F}}$ are listed in the Appendix. It should be pointed out that $\mathbf{G}$ is a combination of the five $2 \mathrm{D}$ Fourier coefficients vectors, whose form is

$$
\mathbf{G}=\left[\begin{array}{lllll}
\mathbf{A}_{m n} & \mathbf{B}_{m n} & \mathbf{C}_{m n} & \mathbf{D}_{m n} & \mathbf{E}_{m n}
\end{array}\right]^{T} .
$$

Form (24), we can easily find that the circular frequency $\omega$ is the square root of eigenvalues and $\mathbf{G}$ is the eigenvectors. When we study the vibration response of the elastic 


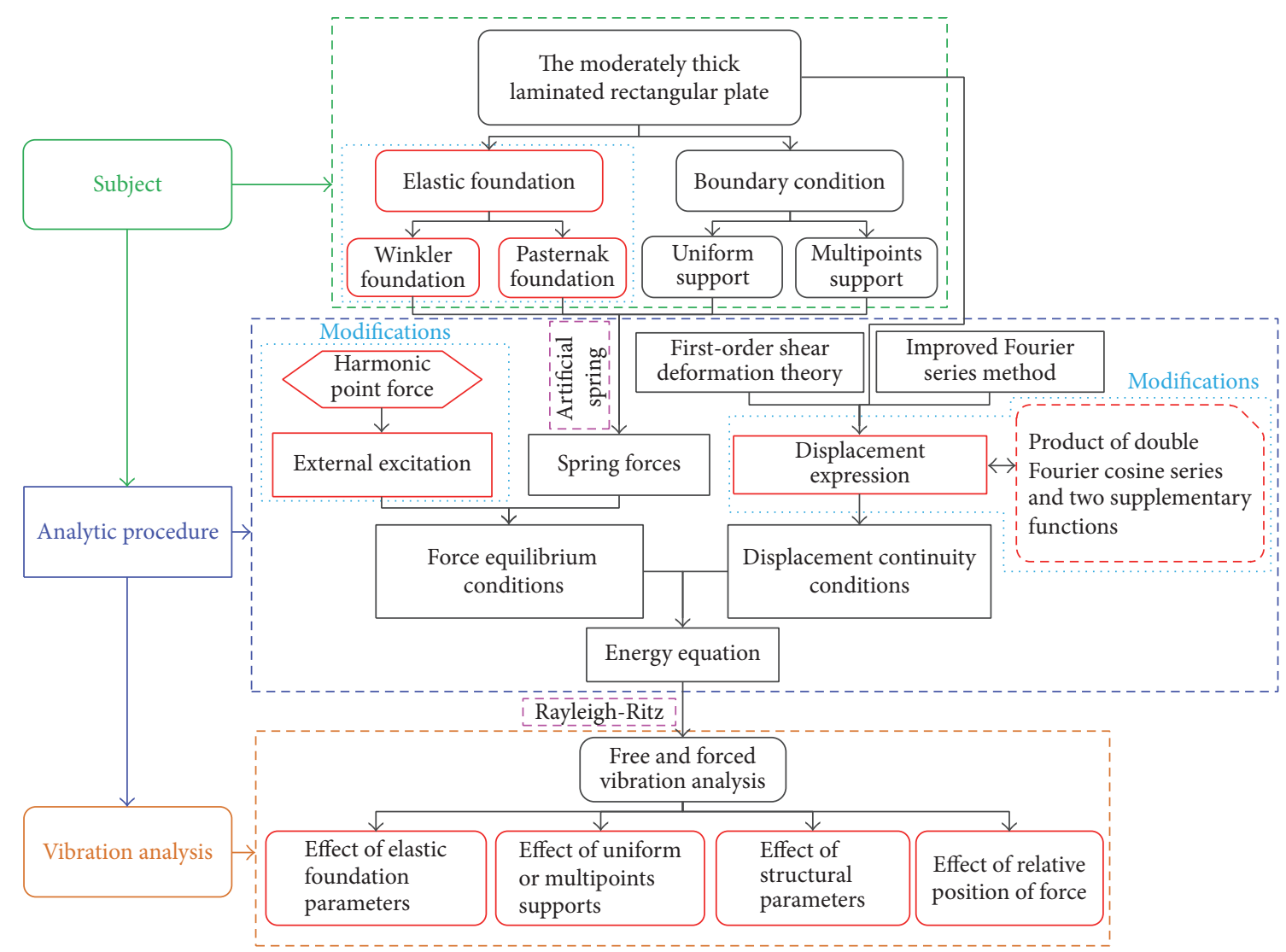

FIGURE 3: The flowchart about the solution for the laminated plate on the elastic foundation.

supported plates resting on the elastic Winkler or Pasternak foundations, $G$ can be obtained by giving a frequency value. Then, the exact displacements expressions of plate can be got by putting $G$ into (21)-(23e). In order to explain the innovation of this paper more intuitively, a brief illustration is given in Figure 3. Compared with [30, 66], this paper has three main original ideas. Firstly, this paper focuses on the effect of elastic foundation on the plate. Secondly, the displacement expressions of the plate are improved. Thirdly, forced vibration response of plate on the elastic foundation is studied by introducing a harmonic point force. In addition, the corresponding results are also given in the next section.

\section{Results and Discussions}

In this section, some calculation cases involving symmetrically and antisymmetrically laminated plates resting on the elastic Winkler and Pasternak foundations are considered, which have various uniform or multipoints supported boundary conditions. Comparisons are made with the available results of literatures and FEM. For the sake of brevity, the letters F, S, and C are used to represent completely free, simply supported, and clamped edges. In addition, a simplified combination of letters (in Table 3 ) is used to characterize the boundary condition of the antisymmetrically laminated plates. For example, the SCSC shows that the laminated plates have $\mathrm{S}, \mathrm{C}, \mathrm{S}$, and $\mathrm{C}$ at the four edges of $x_{0}, y_{0}, x_{a}$, and $y_{b}$, respectively. Besides, material properties of the elastic lamina are supposed as

$$
\begin{aligned}
& \text { Material I: } E_{1} / E_{2}=10 ; G_{12}=G_{13}=0.5 E_{2} ; G_{23}= \\
& 0.2 E_{2} ; \mu_{12}=0.25 ; \mu_{12} E_{1}=\mu_{21} E_{2} \\
& \text { Material II: } E_{1} / E_{2}=40 ; G_{12}=G_{13}=0.6 E_{2} ; G_{23}= \\
& 0.5 E_{2} ; \mu_{12}=0.25 ; \mu_{12} E_{1}=\mu_{21} E_{2}
\end{aligned}
$$

3.1. Convergence Analysis. For the displacement admissible functions constructed in (21)-(23e), the appropriate truncation value should be set in numerical evaluation. The size of the values of $M$ and $N$ is the direct representation of the convergence of the method. Table 1 shows the convergence of the first eight frequency parameters $\Omega$ of the angle-ply $\left(0 / 90^{\circ}\right)$ rectangular laminated plates on the elastic Winkler foundation. The geometrical dimensions are $a / b=1, h / a=$ 0.1 , the material type is Material $I$, and the foundation parameters are $k_{W}=10$ and $k_{S}=0$.

From Table 1, we can find that the present method shows good convergence. For example, for the free plate on the Winkler foundation, the biggest difference for the worst case which is made is the contrast of $8 \times 8$ and $18 \times 18$ being less than $0.13 \%$, while the biggest difference for the worst case which is made is the contrast of $14 \times 14$ and $22 \times 22$ being less than $0.018 \%$. It is not difficult to find that the biggest difference for the worst case which is made is the contrast of $18 \times 18$ and $22 \times 22$ being zero. In order to make the results 
TABLE 1: Convergence of frequency parameter $\Omega$ for angle-ply $\left(0 / 90^{\circ}\right)$ rectangular laminate plates with free and CCCC boundary constraints (Material I).

\begin{tabular}{|c|c|c|c|c|c|c|c|c|c|}
\hline \multirow{2}{*}{$\mathrm{BC}$} & \multirow{2}{*}{$M \times N$} & \multicolumn{8}{|c|}{ Mode number } \\
\hline & & 1 & 2 & 3 & 4 & 5 & 6 & 7 & 8 \\
\hline \multirow{8}{*}{ FFFF } & $8 \times 8$ & 3.147 & 3.147 & 3.162 & 5.392 & 10.299 & 10.563 & 13.076 & 13.076 \\
\hline & $10 \times 10$ & 3.147 & 3.147 & 3.162 & 5.388 & 10.299 & 10.563 & 13.071 & 13.071 \\
\hline & $12 \times 12$ & 3.147 & 3.147 & 3.162 & 5.386 & 10.299 & 10.563 & 13.069 & 13.069 \\
\hline & $14 \times 14$ & 3.147 & 3.147 & 3.162 & 5.386 & 10.299 & 10.563 & 13.068 & 13.068 \\
\hline & $16 \times 16$ & 3.147 & 3.147 & 3.162 & 5.385 & 10.299 & 10.563 & 13.068 & 13.068 \\
\hline & $18 \times 18$ & 3.147 & 3.147 & 3.162 & 5.385 & 10.299 & 10.563 & 13.067 & 13.067 \\
\hline & $20 \times 20$ & 3.147 & 3.147 & 3.162 & 5.385 & 10.299 & 10.563 & 13.067 & 13.067 \\
\hline & $22 \times 22$ & 3.147 & 3.147 & 3.162 & 5.385 & 10.299 & 10.563 & 13.067 & 13.067 \\
\hline \multirow{8}{*}{ CССС } & $8 \times 8$ & 13.581 & 24.121 & 24.121 & 31.944 & 38.209 & 38.448 & 44.141 & 44.141 \\
\hline & $10 \times 10$ & 13.580 & 24.119 & 24.119 & 31.942 & 38.205 & 38.444 & 44.137 & 44.137 \\
\hline & $12 \times 12$ & 13.580 & 24.119 & 24.119 & 31.941 & 38.204 & 38.443 & 44.135 & 44.135 \\
\hline & $14 \times 14$ & 13.580 & 24.119 & 24.119 & 31.940 & 38.203 & 38.443 & 44.134 & 44.134 \\
\hline & $16 \times 16$ & 13.580 & 24.118 & 24.118 & 31.940 & 38.203 & 38.443 & 44.134 & 44.134 \\
\hline & $18 \times 18$ & 13.580 & 24.118 & 24.118 & 31.940 & 38.203 & 38.442 & 44.133 & 44.133 \\
\hline & $20 \times 20$ & 13.580 & 24.118 & 24.118 & 31.940 & 38.203 & 38.442 & 44.133 & 44.133 \\
\hline & $22 \times 22$ & 13.580 & 24.118 & 24.118 & 31.940 & 38.203 & 38.442 & 44.133 & 44.133 \\
\hline
\end{tabular}

TABLE 2: Frequency parameters $\Omega$ for angle-ply $\left(0 / 90^{\circ} / 0\right)$ square plate with simply supported boundary constraints and different foundation parameters and length-thickness ratios (Material II).

\begin{tabular}{|c|c|c|c|c|c|c|}
\hline \multirow{2}{*}{$k_{W}$} & \multirow{2}{*}{$k_{S}$} & \multirow{2}{*}{ Method } & \multicolumn{4}{|c|}{$a / h$} \\
\hline & & & 50 & 20 & 10 & 5 \\
\hline \multirow{3}{*}{0} & \multirow{3}{*}{0} & Shen et al. [67] & 18.689 & 17.483 & 14.702 & 10.263 \\
\hline & & Present & 18.645 & 17.501 & 14.730 & 10.247 \\
\hline & & Error (\%) & 0.239 & 0.101 & 0.193 & 0.154 \\
\hline \multirow{3}{*}{100} & \multirow{3}{*}{0} & Shen et al. [67] & 21.152 & 20.132 & 17.753 & 14.244 \\
\hline & & Present & 21.155 & 20.148 & 17.776 & 14.233 \\
\hline & & Error (\%) & 0.016 & 0.078 & 0.129 & 0.078 \\
\hline \multirow{3}{*}{100} & \multirow{3}{*}{10} & Shen et al. [67] & 25.390 & 24.536 & 22.596 & 19.879 \\
\hline & & Present & 25.393 & 24.549 & 22.614 & 19.870 \\
\hline & & Error (\%) & 0.013 & 0.052 & 0.080 & 0.047 \\
\hline
\end{tabular}

more accurate, all the truncated values of $M$ and $N$ are 18 in the next calculations.

3.2. The Uniform Supported Plate on Elastic Foundations. In this section, free and forced vibration characteristics of the thin and moderately thick plate are discussed. The accuracy of the present method is verified by being compared with the results of Shen et al. [67]. The first frequency parameters $\Omega$ of a three-layered square plate which are simply supported and rest on different elastic foundations are displayed in Table 2. From the table, we can see that the first frequency increases when the two kinds of foundation parameters and the lengththickness ratios $a / h$ increase. In addition, this method is also applicable to the analysis of thin plates. In Table 3, the first six frequency parameters $\Omega$ of the two angle-ply $\left(0 / 90^{\circ}\right)$ clamped square thin plates on the Winkler foundation are given. The geometry parameters of the plate layers are $a / b=1$, $h / b=0.002$, and the material type is Material II. The results obtained by the presented method are in good agreement with the FEM results.

For laminated plate on elastic Pasternak foundation, it is significant to study the change of natural frequency under various boundary conditions. Table 4 shows the first three frequency parameters $\Omega$ for the two-layered $\left[+45^{\circ} /-45^{\circ}\right]$ rectangular plate. It lists the change of $\Omega$ of the plate which rests on the elastic Pasternak-type foundation. There are six kinds of boundary constraints, that is, FFFF, FSFS, FCFC, SSSS, and CCCC. Five kinds of anisotropic ratios $E_{1} / E_{2}$ are given, which are $10,20,30,40$, and 50. In addition, two foundation parameters are $k_{W}=100$ and $k_{S}=10$, respectively. An interesting phenomenon is that the increase of anisotropic ratio has little effect on the natural frequency. But the frequency parameters increase in general with the binding force of the BC increasing as exhibited in Table 4. 
TABLE 3: Frequency parameter $\Omega$ for angle-ply $\left(0 / 90^{\circ}\right)$ square thin plate on the Winkler foundation with CCCC boundary condition (Material II).

\begin{tabular}{cccccccc}
\hline \multirow{2}{*}{$k_{W}$} & Method & \multicolumn{5}{c}{ Mode shape } & \multicolumn{1}{c}{6} \\
\hline \multirow{2}{*}{0} & Present & 24.138 & 49.879 & 49.879 & 68.085 & 92.529 & 92.703 \\
& FEM & 24.281 & 50.210 & 50.210 & 68.589 & 93.418 & 93.503 \\
\hline \multirow{2}{*}{10} & Present & 24.344 & 49.979 & 49.979 & 68.159 & 92.583 & 92.757 \\
& FEM & 24.488 & 50.412 & 50.412 & 68.664 & 93.502 & 93.658 \\
\hline \multirow{2}{*}{100} & Present & 26.127 & 50.871 & 50.871 & 68.816 & 93.068 & 93.240 \\
& FEM & 26.085 & 51.311 & 51.311 & 69.362 & 93.938 & 94.081 \\
\hline
\end{tabular}

TABLE 4: Frequency parameters $\Omega$ for angle-ply $\left(+45^{\circ} /-45^{\circ}\right)$ rectangular plate with different BC and anisotropic degrees.

\begin{tabular}{|c|c|c|c|c|c|c|c|}
\hline \multirow{2}{*}{$E_{1} / E_{2}$} & \multirow{2}{*}{ Mode number } & \multicolumn{6}{|c|}{ Boundary condition } \\
\hline & & FFFF & FSFS & FCFC & SSSS & SCSC & CCCC \\
\hline \multirow{3}{*}{10} & 1 & 10.000 & 15.642 & 17.433 & 32.963 & 35.789 & 39.335 \\
\hline & 2 & 14.289 & 24.010 & 25.816 & 44.438 & 46.692 & 49.321 \\
\hline & 3 & 22.965 & 34.155 & 36.133 & 59.647 & 61.544 & 63.734 \\
\hline \multirow{3}{*}{20} & 1 & 10.000 & 15.947 & 17.864 & 35.833 & 38.249 & 41.351 \\
\hline & 2 & 14.315 & 25.272 & 26.912 & 48.419 & 50.112 & 52.108 \\
\hline & 3 & 23.021 & 36.639 & 39.319 & 64.457 & 65.724 & 67.269 \\
\hline \multirow{3}{*}{30} & 1 & 10.000 & 16.194 & 18.225 & 37.841 & 40.020 & 42.822 \\
\hline & 2 & 14.334 & 26.253 & 27.782 & 51.054 & 52.433 & 54.058 \\
\hline & 3 & 23.058 & 38.118 & 40.927 & 67.556 & 68.497 & 69.683 \\
\hline \multirow{3}{*}{40} & 1 & 10.000 & 16.409 & 18.542 & 39.381 & 41.388 & 43.956 \\
\hline & 2 & 14.348 & 27.069 & 28.510 & 52.985 & 54.153 & 55.523 \\
\hline & 3 & 23.085 & 39.216 & 42.035 & 69.768 & 70.511 & 71.466 \\
\hline \multirow{3}{*}{50} & 1 & 10.000 & 16.604 & 18.825 & 40.616 & 42.485 & 44.862 \\
\hline & 2 & 14.359 & 27.770 & 29.137 & 54.476 & 55.488 & 56.671 \\
\hline & 3 & 23.105 & 40.097 & 42.891 & 71.438 & 72.050 & 72.846 \\
\hline
\end{tabular}

The effects of the boundary spring stiffness on free vibration behaviors of the laminated plate are investigated based on parametric study, which can deepen the understanding. Five elastic boundary restraint ratios are $\Gamma_{\beta}(\beta=u, v, w$, $\phi_{x}$, and $\left.\phi_{y}\right)$, that is, $\Gamma u=k_{u} / D ; \Gamma v=k_{v} / D ; \Gamma w=$ $k_{w} / D ; \Gamma x=K_{x} / D ; \Gamma y=K_{y} / D . D$ is the structural stiffness coefficient, whose expression is $D=E_{2} h^{3} / 12(1-$ $\left.\mu_{12}{ }^{2}\right)$. Figure 4 exhibits the curves of lowest three frequency parameters $\Omega$ with the change of restraint parameters for the laminated composite rectangular plates resting on the elastic foundation. The unsymmetrical lamination scheme $\left[45^{\circ} /-45^{\circ} / 45^{\circ} /-45^{\circ}\right]$ of the composite plate is brought. The laminated plates are supported by a set of spring component on the four edges with stiffness values varying from $10^{-8} \mathrm{D}$ to $10^{12} \mathrm{D}$. The geometry constants of the plate layers are $a / b=2, h / b=0.2$, and the material type is Material II. Two foundation parameters are $k_{W}=10$ and $k_{S}=10$, respectively. From the figures, it can be seen clearly that when the boundary spring stiffness parameter is less than $10^{-2} \mathrm{D}$, the change of the spring stiffness values has little effect on the natural frequency of the laminated plate. The laminated plate frequency will increase quickly with the increase of the stiffness when the value changes between $10^{-2} \mathrm{D}$ and $10^{3} \mathrm{D}$. But when the value is more than $10^{3} \mathrm{D}$, the natural frequency of the plate is almost constant. In addition, we can also find that the greatest impact on the frequency is the spring parameters $\Gamma u$ and $\Gamma v$. For $\Gamma x$ and $\Gamma y$, they almost have no effect on the frequency. The interesting thing is that $\Gamma w$ has no effect on the first two frequencies, while the effect on the third frequency is greater than the elastic spring parameters of $\Gamma u$ and $\Gamma v$.

As mentioned earlier, the isotropic plates can be easily obtained by letting $E_{1}=E_{2}$ and $G_{12}=G_{13}=G_{23}=E_{1} /(2+$ $\left.2 \mu_{12}\right)$. Figure 5 gives the transverse vibration displacement level on $z$ direction of isotropic plates in the frequency range of $0-800 \mathrm{~Hz}$ by exerting a harmonic point force on the simple supported plate. The amplitude of the point force is $1 \mathrm{~N}$. It will be applied to the following cases of forced vibrations. The position of point force is at $(a / 10, b / 10)$. The positions of the two observation points are at $(a / 2, b / 2)$ and $(7 a / 8,7 b / 8)$. Material parameters of plate are $E_{1}=E_{2}=1.85 \mathrm{e} 11 \mathrm{~N} / \mathrm{m}^{2}$, $\mu_{12}=0.3$, and $\rho=1600 \mathrm{~kg} / \mathrm{m}^{2}$. The geometry parameters of 

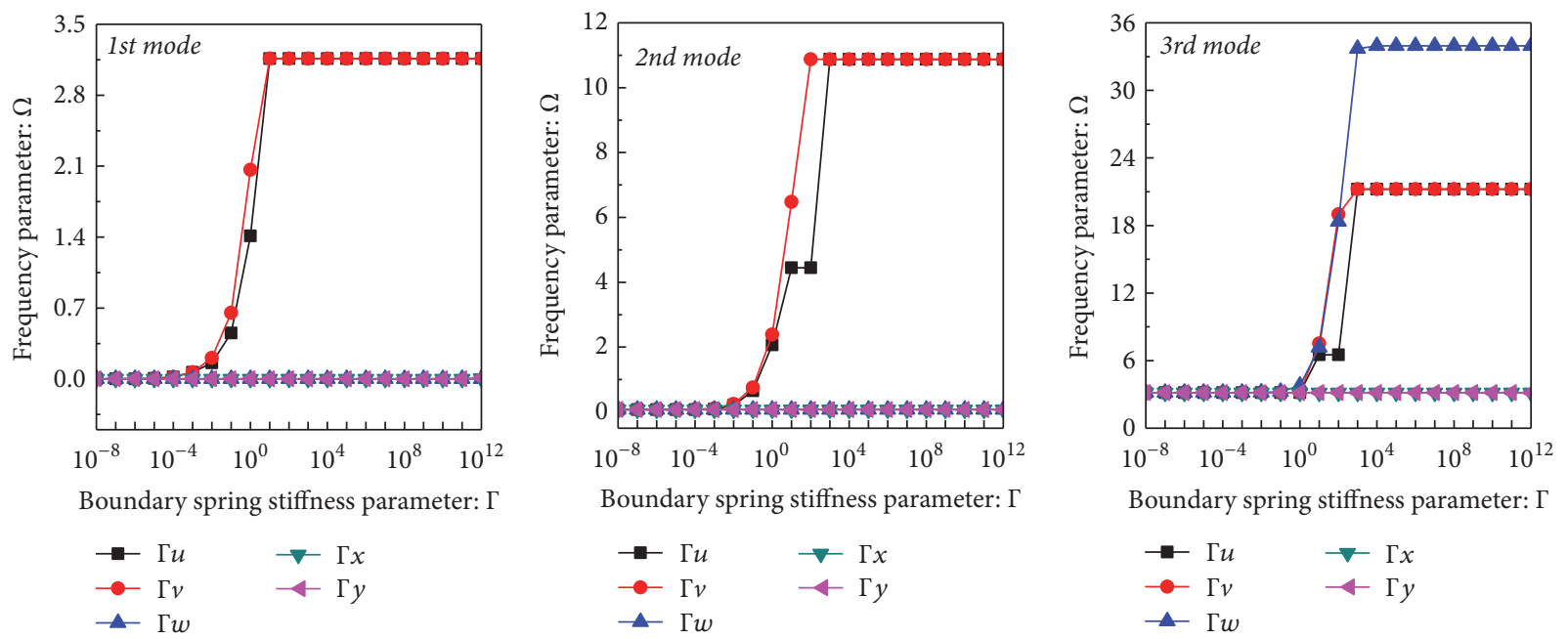

FIGURE 4: Frequency parameters $\Omega$ versus elastic spring stiffness parameter $\Gamma$ for the plate with uniform boundary.

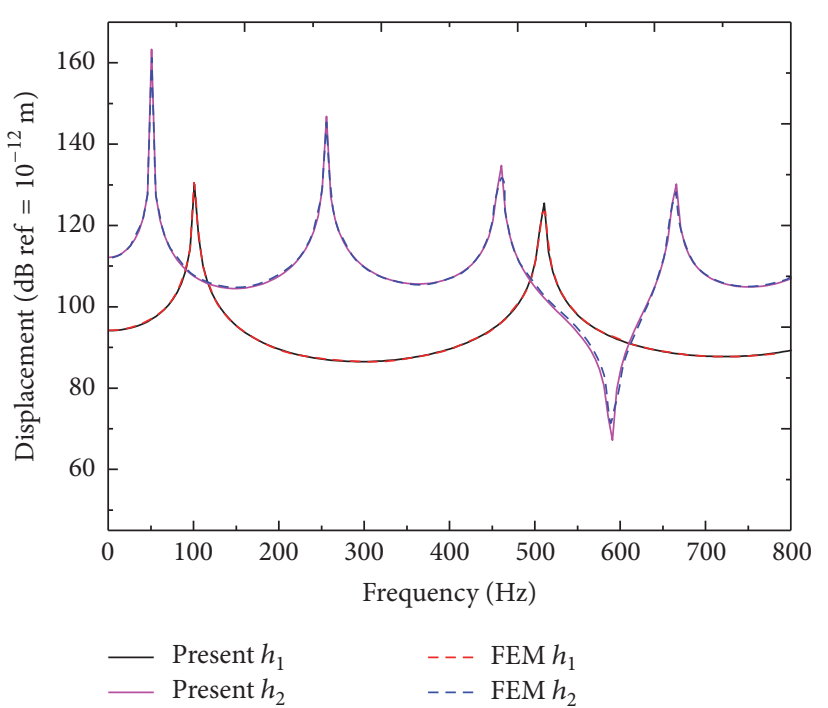

(a) Displacement response at $(a / 2, b / 2)$

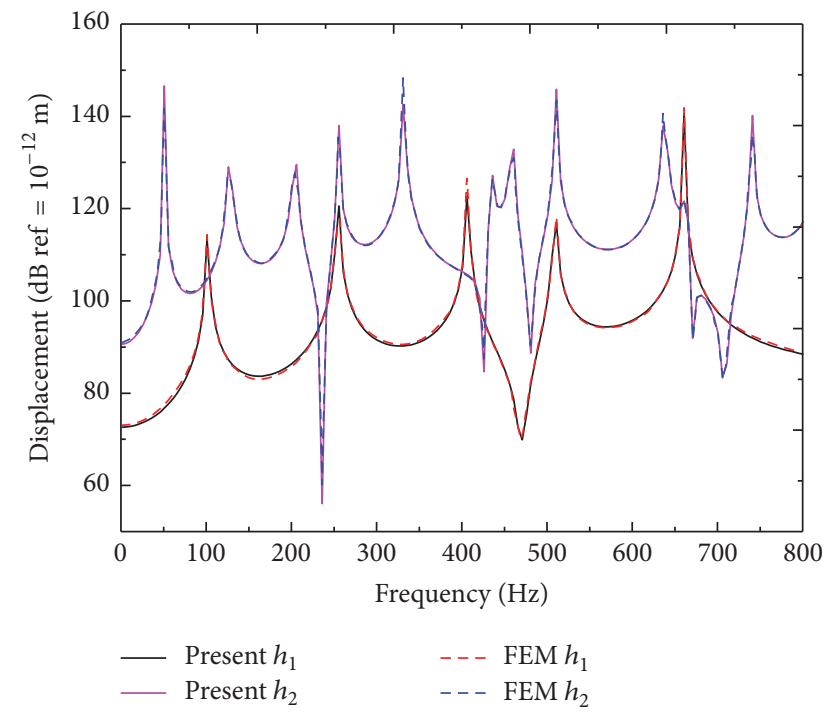

(b) Displacement response at $(7 a / 8,7 b / 8)$

FIGURE 5: Vibration displacement response of the simple support isotropic plate with varying thickness.

the plate are $a / b=1, h_{1} / b=0.01$, and $h_{2} / b=0.005$. The results obtained by the present method are compared with those obtained by FEM which show good agreement. It shows that this method is also applicable to the thin plate structures. As we can see from Figure 5, the thickness of the plate has a great effect on the displacement response. The vibration displacement level increases with the decrease of the plate thickness.

In order to further study the effect of elastic support on the transverse vibration response of the four-layered $\left[0 / 90^{\circ} \%\right.$ $\left.0 / 90^{\circ}\right]$ rectangular plate, three elastic boundary conditions are proposed according to Figure 4 . They are $E^{1}=10^{-1} D$, $E^{2}=10^{1} D$, and $E^{3}=10^{2} D$. The geometry constants of the plate layers are $a / b=2, h / b=0.2$, and the material type is Material II. Two foundation parameters are $k_{W}=100$ and $k_{S}=100$, respectively. The position of point force is at $(a / 8, b / 8)$. The positions of the two observation points are at $(a / 4, b / 4)$ and $(7 a / 8,7 b / 8)$. It can be seen from Figure 6 that the values of natural frequencies increase in the frequency range of $0-1000 \mathrm{~Hz}$ with the increase of the boundary springs stiffness. Moreover, the vibration displacements decrease with the increase of the boundary springs stiffness.

3.3. The Multipoints Supported Plate on Elastic Foundations. In this section, the free and forced vibrations of laminated plates on elastic foundation with various multipoints supported boundary constraints are investigated. For this plate model, the geometrical dimensions are $a=b=1 \mathrm{~m}, h=$ $0.2 \mathrm{~m}$, and the material type is Material II. In order to simplify, various constraint values of multipoints supports are set. For example, K7 expresses that the stiffness value of five kinds of spring is $10^{7}$. As shown in Table 5, the first six of $\Omega$ for 
TABLE 5: Frequency parameter $\Omega$ for angle-ply $\left(0 / 90^{\circ}\right)$ square plate with 8-point elastic supported boundary constraints and different foundation parameters (Material II).

\begin{tabular}{|c|c|c|c|c|c|c|c|c|}
\hline \multirow{2}{*}{$k_{W}$} & \multirow{2}{*}{$k_{S}$} & \multirow{2}{*}{ Method } & \multicolumn{6}{|c|}{ Mode shape } \\
\hline & & & 1 & 2 & 3 & 4 & 5 & 6 \\
\hline \multirow{2}{*}{0} & \multirow{2}{*}{0} & Present & 1.185 & 1.218 & 1.218 & 1.923 & 2.944 & 2.944 \\
\hline & & FEM & 1.202 & 1.219 & 1.219 & 1.856 & 2.962 & 2.962 \\
\hline \multirow{2}{*}{10} & \multirow{2}{*}{0} & Present & 1.218 & 1.218 & 1.923 & 3.377 & 4.280 & 4.280 \\
\hline & & FEM & 1.219 & 1.219 & 1.856 & 3.374 & 4.388 & 4.388 \\
\hline \multirow{2}{*}{100} & \multirow{2}{*}{0} & Present & 1.218 & 1.218 & 1.924 & 10.070 & 10.254 & 10.254 \\
\hline & & FEM & 1.219 & 1.219 & 1.856 & 10.006 & 10.625 & 10.625 \\
\hline
\end{tabular}

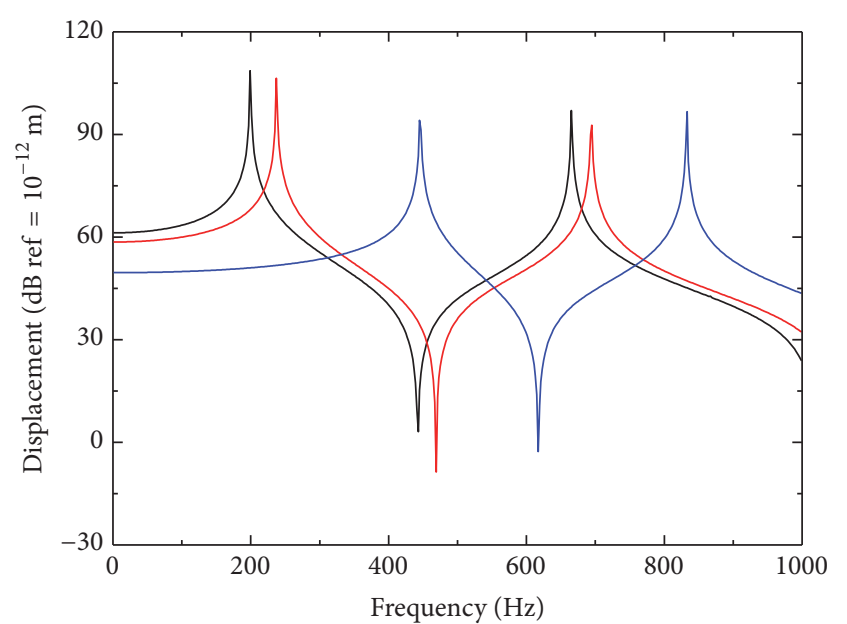

$-E^{1} E^{1} E^{1} E^{1}$
$-E^{2} E^{2} E^{2} E^{2}$
$-E^{3} E^{3} E^{3} E^{3}$

(a) Displacement response at $(a / 4, b / 4)$

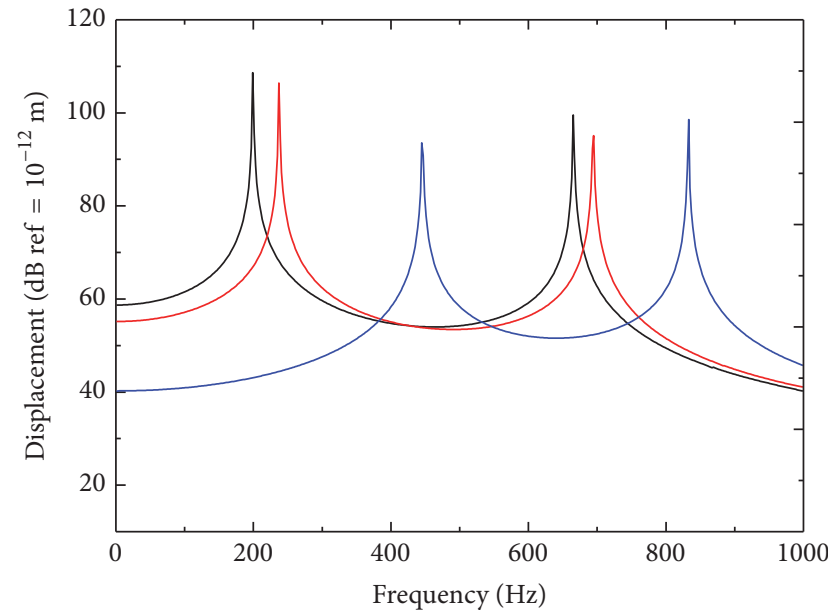

$-E^{1} E^{1} E^{1} E^{1}$
$-E^{2} E^{2} E^{2} E^{2}$
$-E^{3} E^{3} E^{3} E^{3}$

(b) Displacement response at $(7 a / 8,7 b / 8)$

FIGURE 6: Vibration displacement response of the laminated foundation plate with various elastic supports.

the plate model under consideration with 8-point support, resting on the Winkler foundations, by using the method proposed in this paper are compared with the results of numerical calculation which use the ABAQUS model. The results of the two solutions are in good agreement with $\mathrm{K} 7$ elastic supported boundary conditions. Besides, there is a cognitive phenomenon that the frequency parameters $\Omega$ increase gradually, especially after the fourth frequency, when the Winkler parameter $k_{W}$ increases.

Based on the conclusions drawn from Table 5, we have proved the accuracy of the present method. So we will directly give some frequency values of the antisymmetric laminated plate with the 8-point K7 elastic supports under the elastic Pasternak foundation. Table 6 shows some of the frequency parameters of the two kinds of cross-ply square plates, that is, angle-ply $\left[0 / 90^{\circ}\right]$ and $\left[0 / 90^{\circ} / 0 / 90^{\circ}\right]$. This plate model is the same as the model considered in Table 4 . It is not hard to find that the natural frequency increases when foundation parameters increase, and the effect of the Winkler parameter $k_{W}$ on the plate frequency is much larger than the Pasternak foundation parameter $k_{s}$. In addition, the frequency of the four-layered plate is a little bigger than the frequency of the two-layered plate. In the following research, we will give the frequency of the plate on the elastic foundation changing with the increase of the number of layers.

In this part, we discuss the effect of boundary spring stiffness on the plate vibration. Here, we set up five kinds of elastic boundary restraint parameters $\Gamma_{\beta}(\beta=u, v, w$, $\phi_{x}$, and $\phi_{y}$ ) of multipoints supports, just like the parameters in Figure 4. Figure 7 exhibits the curves of lowest three frequency parameters $\Omega$ with the change of restraint parameters of the laminated composite rectangular plates resting on the elastic foundation. The symmetrical lamination scheme $\left[0 / 90^{\circ} / 0 / 90^{\circ} / 0\right]$ of the composite plate is studied. This laminated plate is supported by a set of spring components on the 8 points with stiffness values varying from $10^{-8} \mathrm{D}$ to $10^{12} \mathrm{D}$. The geometry constants of the plate layers are $a / b=1, h / b=0.2$. The material properties and the nondimensional foundation parameters are same as the parameters in Figure 4. From the figures, we can clearly see that the growth trend of the five parameters curves is the same as the growth trend in Figure 4. But the different place is that the effect of $\Gamma w$ on the third frequency is same as the elastic spring parameters $\Gamma u$ and $\Gamma v$ in Figure 7. Besides, frequencies 
TABLE 6: Frequency parameter $\Omega$ for two cross-ply square plates with 8-point elastic supported boundary constraints and different foundation parameters (Material II).

\begin{tabular}{|c|c|c|c|c|c|c|c|}
\hline \multirow{2}{*}{$k_{W}$} & \multirow{2}{*}{$k_{S}$} & \multicolumn{3}{|c|}{$0 / 90^{\circ}$} & \multicolumn{3}{|c|}{$0 / 90^{\circ} / 0 / 90^{\circ}$} \\
\hline & & 2 & 4 & 6 & 2 & 4 & 6 \\
\hline \multirow{3}{*}{0} & 0 & 1.217 & 1.923 & 2.944 & 1.219 & 1.926 & 3.146 \\
\hline & 10 & 1.218 & 1.924 & 10.531 & 1.219 & 1.926 & 10.648 \\
\hline & 100 & 1.218 & 1.924 & 22.804 & 1.219 & 1.926 & 23.149 \\
\hline \multirow{3}{*}{10} & 0 & 1.218 & 3.377 & 4.280 & 1.219 & 3.379 & 4.423 \\
\hline & 10 & 1.218 & 3.385 & 10.982 & 1.219 & 3.385 & 11.094 \\
\hline & 100 & 1.218 & 3.390 & 22.804 & 1.219 & 3.390 & 23.149 \\
\hline \multirow{3}{*}{100} & 0 & 1.218 & 10.070 & 10.254 & 1.219 & 10.071 & 10.316 \\
\hline & 10 & 1.218 & 10.073 & 14.414 & 1.219 & 10.073 & 14.501 \\
\hline & 100 & 1.218 & 10.074 & 22.804 & 1.219 & 10.074 & 23.149 \\
\hline
\end{tabular}
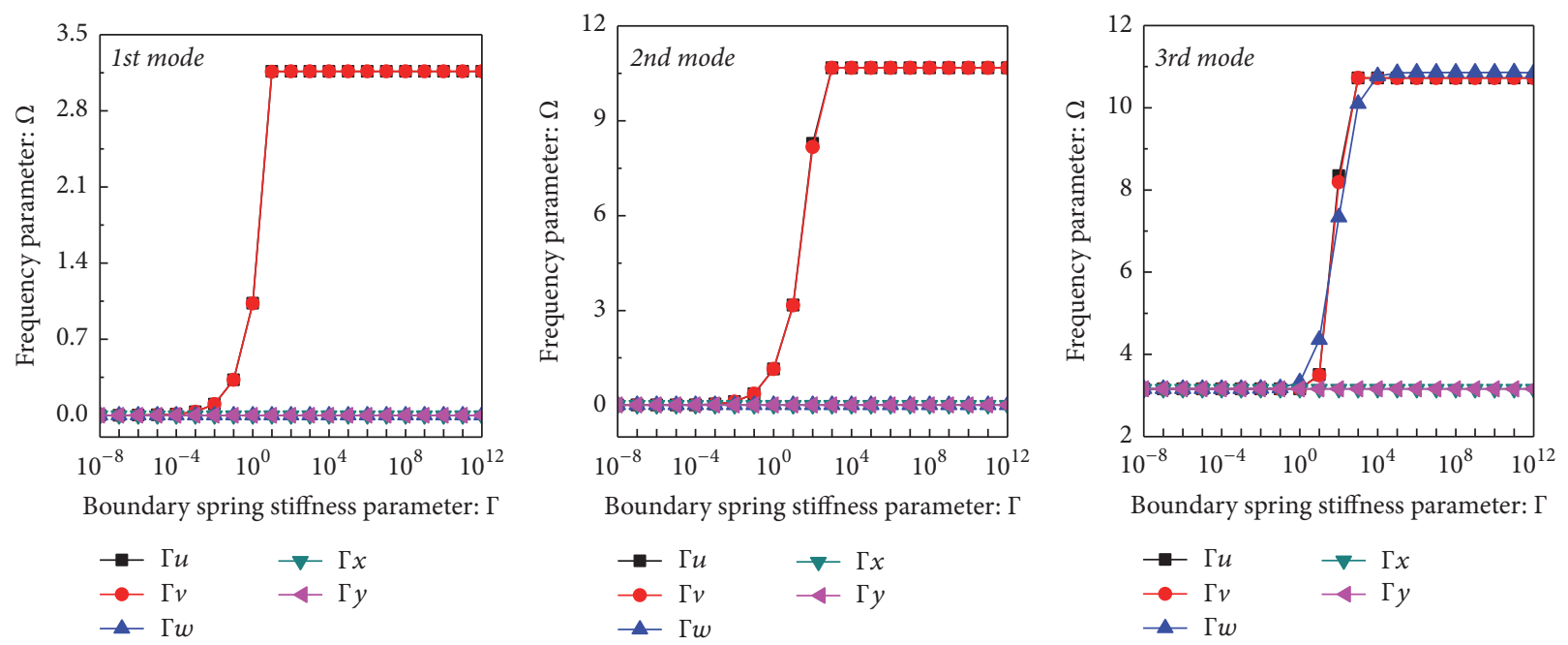

FIGURE 7: Frequency parameters $\Omega$ versus elastic parameter $\Gamma$ for the plate with 8-point supported boundary conditions.

are different. It shows that the different supports have a great influence on the frequency.

As we all know, the bearing capacity of the composite lamina is directly influenced by the fibers direction and the layer's number. Therefore, it is of great significance to study the effect of layer's number and angles on the vibration characteristics of laminated plates on the elastic foundations. Figure 8 depicts the first three-order frequency parameters $\Omega$ of the laminated plate on the Pasternak-type foundation. The schemes of layer's number and angles are $[0 / \theta]_{n}$, where $n$ stands for the half of the layer's number and $\theta$ is the angle. In this figure, there are four kinds of angle schemes which are $\theta=30^{\circ}, 45^{\circ}, 60^{\circ}$, and $90^{\circ}$. According to Figure 7 , the clamped boundary constraint is simulated by setting the values of five parameters to greater than $10^{3} \mathrm{D}$. Therefore, the elastic boundary restraint parameter $\Gamma_{\beta}\left(\beta=u, v, w, \phi_{x}\right.$, and $\left.\phi_{y}\right)$ is $10^{6}$. The layers of the plate have equal thickness and the material type is Material II. The geometric parameters are $a / b=2, h / b=0.2$. In addition, two linear foundation parameters are $k_{W}=100$ and $k_{S}=10$. Initially, the frequencies begin to increase rapidly with the increase of layer's number. Then, the frequencies tend to be stable until the number of layers exceeds 12. For the first and second frequencies, the values increase when the angles increase. However, this phenomenon does not apply to the third-order frequency.

The laminated plates on the elastic foundation with various multipoints supports extensively exist in engineering applications, like point supported glass curtain wall, spotwelded plate, and so on. This requires us to understand the vibration characteristics of multipoint supported plate. Figure 9 considers the multipoints supported plate resting on the Pasternak foundation. These points are evenly distributed on the four edges. The boundary restraint parameter $\Gamma_{\beta}(\beta=$ $u, v, w, \phi_{x}$, and $\left.\phi_{y}\right)$ is $10^{6}$ and the two foundation parameters are $k_{W}=100$ and $k_{S}=10$. The geometrical dimensions and material properties are the same as Figure 8. Based on the conclusions drawn from Figure 8, the lowest four frequency parameters $\Omega$ of the $\left[0 / 45^{\circ}\right]_{6}$ layered plate which is rested on Pasternak-type foundation against the number of points $q$ are depicted in Figure 9. In addition, we also give the $\Omega$ of the same plate model with the equivalent uniform support as the contrast data. The number of supported points on the four edges gradually increases from 8 to 70 . When 

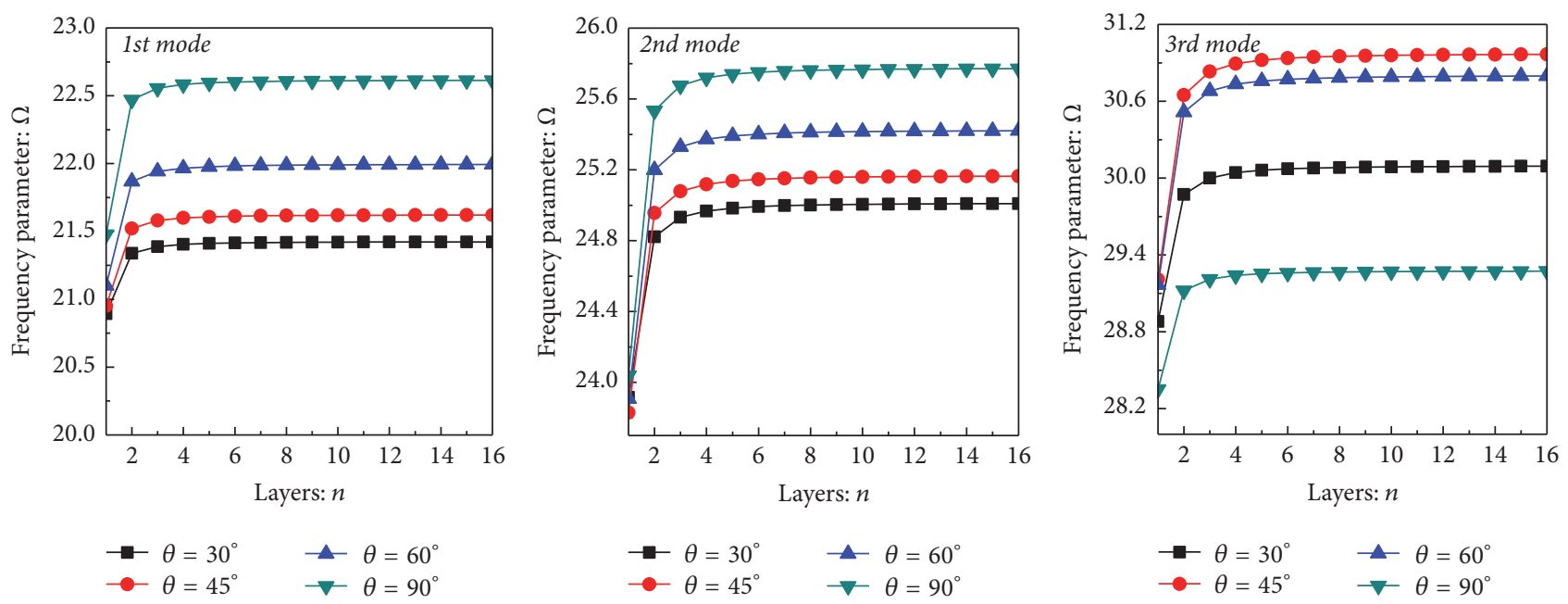

FIGURE 8: Frequency parameters $\Omega$ versus number of layers $n$ for a $[0 / \theta]_{n}$ layered plate with middle-points supported boundary conditions.

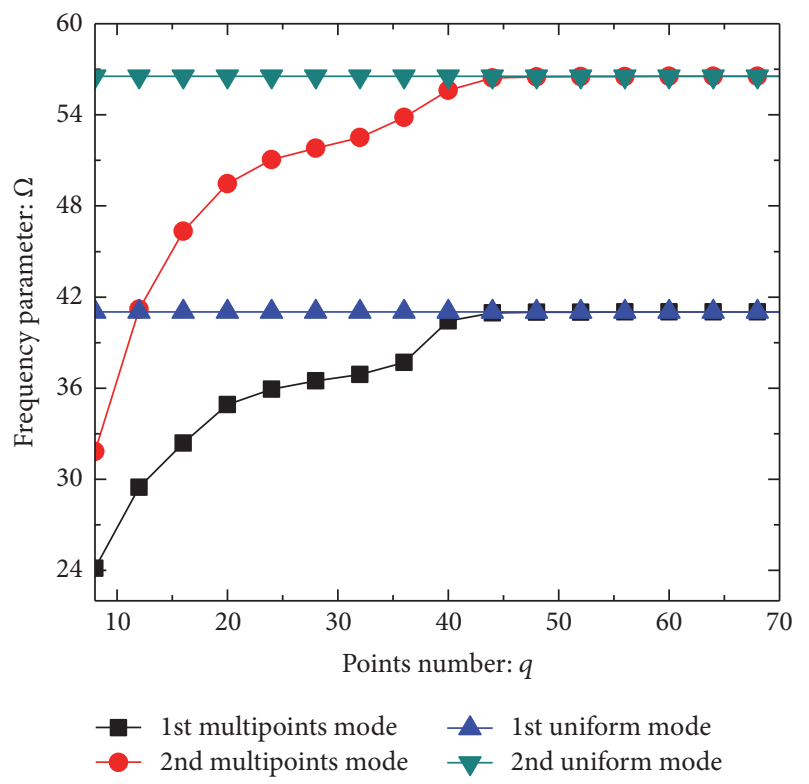

(a) The 1st and 2nd frequency parameters

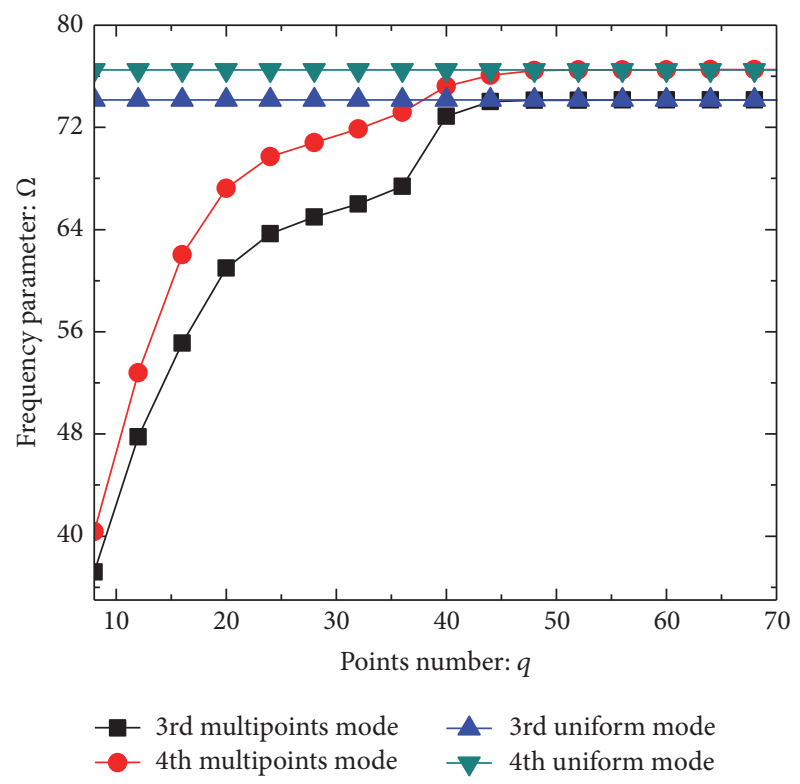

(b) The 3rd and 4th frequency parameters

FIGURE 9: Frequency parameters $\Omega$ versus points number $q$ for layered plate with multipoints supported boundary conditions.

the number of supported points increases, the first four frequency parameters increase firstly. Then, they tend to be stable and are similar to the frequencies of the same plate with uniform support when the number of points exceeds 48 . The biggest difference of the worst case which is made is the contrast of 44 points and uniform support one being less than $0.182 \%$. Then the biggest difference of the worst case which is made is the contrast of 48 points and uniform support one being about $0.069 \%$. So, the natural frequencies of these point supports are finally converged to the ones of the corresponding uniform supported plate. Therefore, the multipoints support can be used to replace the uniform boundary conditions. For example, multiple bolts are tightened to simulate the uniform clamped boundary conditions in the experiment.

Figure 10 gives the transverse vibration displacement level on $z$ direction of isotropic plates in the frequency range of $0-400 \mathrm{~Hz}$. The plate with simple support on the four endpoints is encouraged by a harmonic point force. The geometry parameters and material parameters of plate are same as Figure 5. The position of point force is at $(a / 10, b / 10)$, and the two observation points are at $(a / 2$, $b / 2)$ and $(7 a / 8,7 b / 8)$, respectively. The results obtained by FEM are given here in order to verify the accuracy of the present method. The vibration response curves at different observation points are very different. These rules are the same 


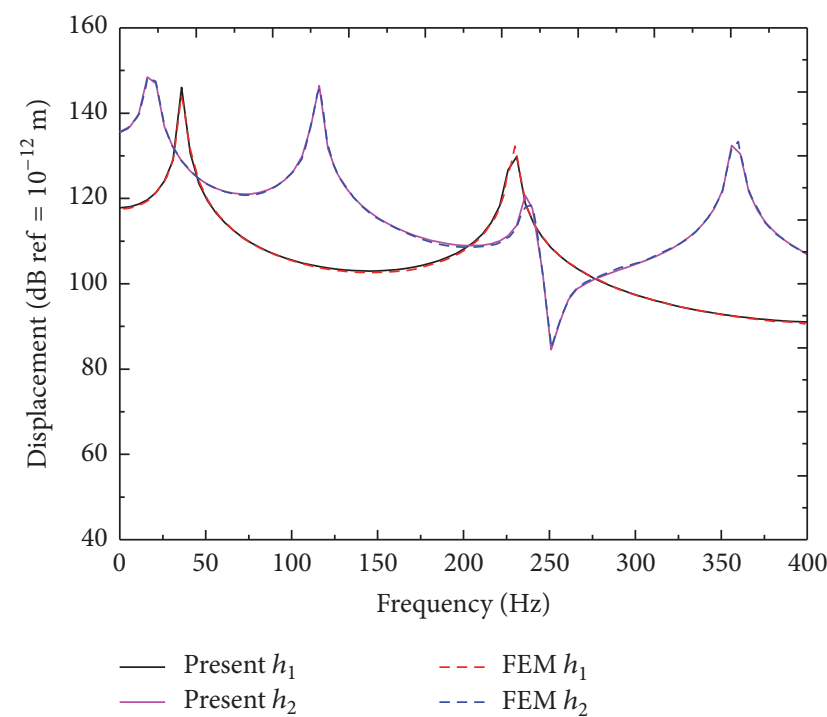

(a) Displacement response at $(a / 2, b / 2)$

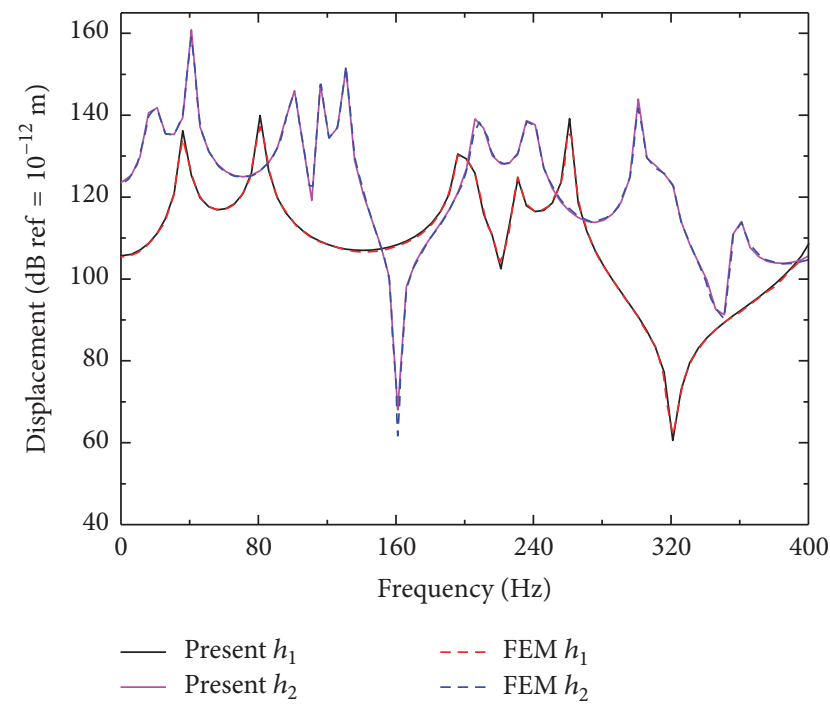

(b) Displacement response at $(7 a / 8,7 b / 8)$

FIGURE 10: Vibration displacement response of the simple supported isotropic plate on endpoints with varying thickness.

as those in Figure 5. It should be pointed out that the number of resonant peaks obviously increases at the observation point which is far from the position of point force.

Figure 11 studies the effect of elastic foundation parameters on the vibration response of the plate with 8-point elastic support. The five kinds of combinations are $k_{W}=10$ and $k_{S}=0, k_{W}=10$ and $k_{S}=10, k_{W}=10$ and $k_{S}=50$, $k_{W}=50$ and $k_{S}=0$, and $k_{W}=100$ and $k_{S}=0$. The boundary condition of plate is $E^{2} E^{2} E^{2} E^{2}$. The geometry constants of the plate layers are $a / b=1, h / b=0.2$, and the material type is Material II. The position of point force is at $(a / 5, b / 5)$. The positions of the two observation points are at $(2 a / 5,2 b / 5)$ and $(7 a / 10,7 b / 10)$. Four groups of comparison curves of vibration displacement levels in the frequency range of $0-1500 \mathrm{~Hz}$ are given in Figure 11. It shows the vibration response with the change of Winkler-type foundation parameters $k_{W}$ in (a) and (b). With the increase of the Winkler parameter $k_{W}$, the natural frequency increases, the displacement response wave moves back in the frequency domain, and the wave crest is attenuated. In (c) and (d) of Figure 11, the effect of Pasternak parameter $k_{S}$ on the vibration response of plate is studied. As we can see, the displacement wave moves back in the frequency domain with the increase of $k_{S}$. Moreover, there is an interesting finding that the peak value is largest when the foundation combination is $k_{W}=10$ and $k_{S}=50$.

At the end of this paper, the three-dimensional view models are adopted to understand the vibration characteristics of multipoints supported laminated plates on the elastic Pasternak foundations. The geometric dimensions of these moderately thick $\left[0 / 45^{\circ}\right]_{6}$ layered plates are $a=b=1 \mathrm{~m}, h=$ $0.2 \mathrm{~m}$, and the material properties are the same as the material I. Five boundary restraint parameters are $\Gamma_{\beta}=10^{6}(\beta=u, v$, $w, \phi_{x}$, and $\phi_{y}$ ). In addition, two linear foundation parameters are $k_{W}=10$ and $k_{S}=10$, respectively. For comparison, mode shapes of the uniform supported plate on the Pasternak foundation and uniform supported plate without foundation are also given in Figure 12. As shown in Figure 12, the mode shapes tend to approach uniform boundary conditions when the number of points increases gradually. In addition, we can intuitively see the effect of the elastic foundation on the mode shapes of plate.

\section{Conclusions}

This paper extends an improved Fourier series solution to solve the free and forced vibration analysis of the moderately thick laminated rectangular plate on the elastic Winkler and Pasternak foundations which has various uniform and multipoints supported boundary constraints. The five displacement functions are all expressed as a series of twodimensional Fourier series which can ignore the influence of boundary conditions. The introduction of two supplementary polynomials of the displacement functions can effectively eliminate the discontinuous or jumping phenomenon on the boundaries. The formulations are based on FSDT and the interaction of plate-foundation model and the artificial spring technique. The different boundary constraints can be easily realized by setting different elastic restraint stiffness. It can effectively simulate the boundary conditions of the plate structures in real world. The results of the present method show good agreement with the results of existing literatures and FEM. The results of free vibration for thin and moderately thick plates with various foundation parameters, different uniform boundary conditions, and multipoint supports are examined in this investigation. In addition, the lamination schemes and geometric parameters have shown a great influence on the vibration frequency of the plate. The effects of the increase of layer's number, changes of the laying angle, and increase of the number of supported points on natural 

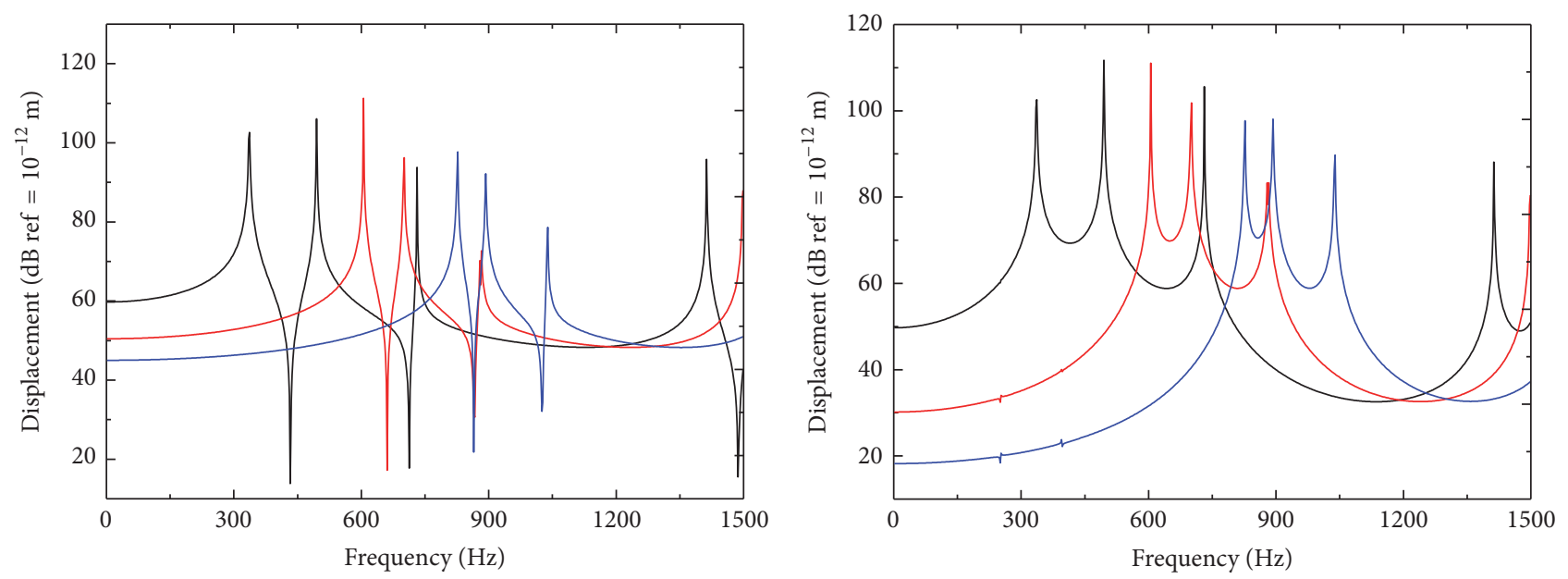

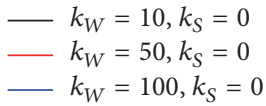

(a) Displacement response at $(2 a / 5,2 b / 5)$

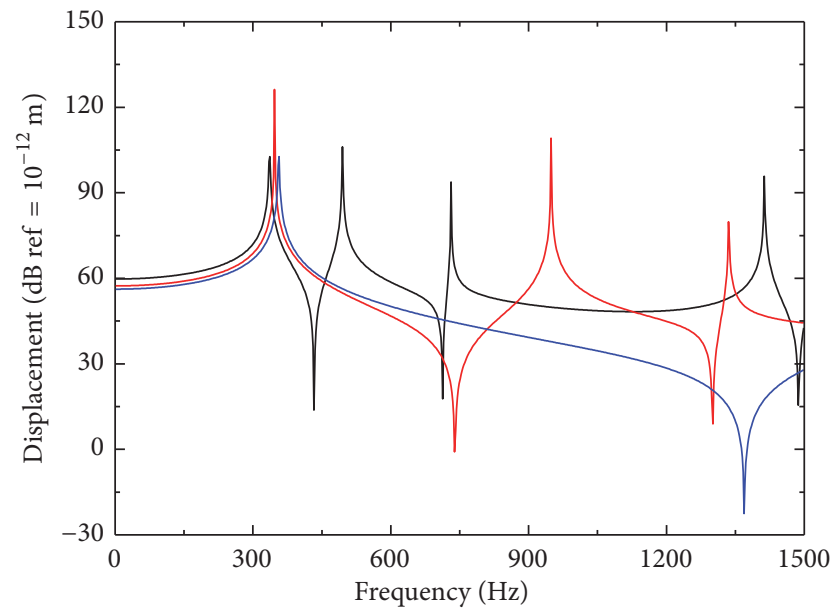

$\begin{aligned} k_{W} & =10, k_{S}=0 \\ k_{W} & =10, k_{S}=10 \\ -k_{W} & =10, k_{S}=50\end{aligned}$

(c) Displacement response at $(2 a / 5,2 b / 5)$

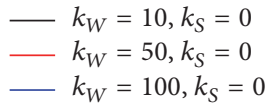

(b) Displacement response at $(7 a / 10,7 b / 10)$

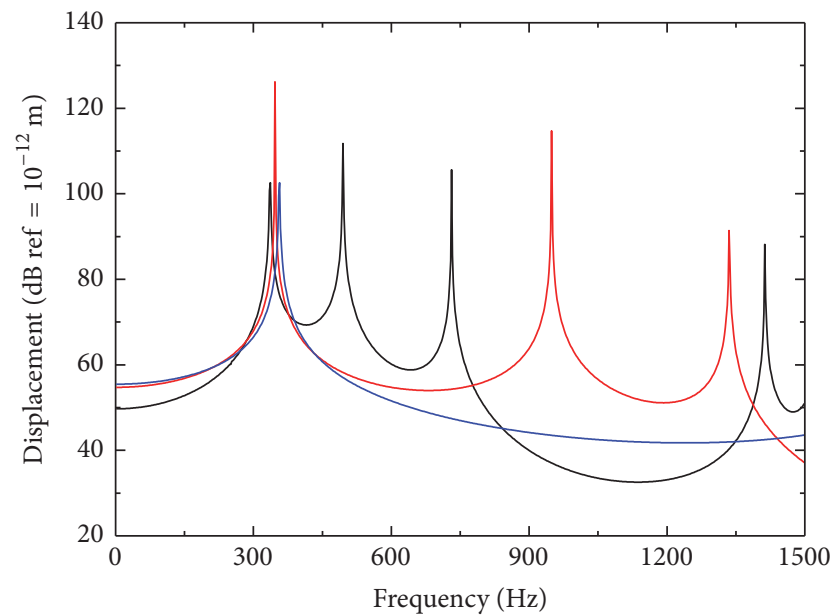

$-k_{W}=10, k_{S}=0$

$k_{W}=10, k_{S}=10$

$-k_{W}=10, k_{S}=50$

(d) Displacement response at $(7 a / 10,7 b / 10)$

FIGURE 11: Vibration displacement response of the 8-point elastic supported laminated plate on the various elastic foundations.

frequency of the plates are presented. The forced vibration response of plate is studied by applying an external harmonic point force. Vibration displacement response of the plate with various thicknesses, elastic boundary constraints, and elastic foundation parameters is investigated, which can provide a benchmark for the future research.

\section{Appendix}

\section{Detailed Expressions of Matrices $K, M$, and $\bar{F}$}

The specific expressions of stiffness matrix $\mathbf{K}$ can be written as follows:

$$
\mathbf{K}=\mathbf{K}_{S}+\mathbf{K}_{B}+\mathbf{K}_{B C}+\mathbf{K}_{U_{f}}+\mathbf{K}_{S P}
$$

$$
=\left[\begin{array}{ccccc}
\mathbf{K}_{u, u}^{S} & \mathbf{K}_{u, v}^{S} & \mathbf{0} & \mathbf{0} & \mathbf{0} \\
\left(\mathbf{K}_{u, v}^{S}\right)^{T} & \mathbf{K}_{v, v}^{S} & \mathbf{0} & \mathbf{0} & \mathbf{0} \\
\mathbf{0} & \mathbf{0} & \mathbf{K}_{w, w}^{S} & \mathbf{K}_{w, \phi_{x}}^{S} & \mathbf{K}_{w, \phi_{y}}^{S} \\
\mathbf{0} & \mathbf{0} & \left(\mathbf{K}_{w, \phi_{x}}^{S}\right)^{T} & \mathbf{K}_{\phi_{x}, \phi_{x}}^{S} & \mathbf{K}_{\phi_{x}, \phi_{y}}^{S} \\
\mathbf{0} & \mathbf{0} & \left(\mathbf{K}_{u, v}^{S}\right)^{T} & \left(\mathbf{K}_{\phi_{x}, \phi_{y}}^{S}\right)^{T} & \mathbf{K}_{\phi_{y}, \phi_{y}}^{S}
\end{array}\right]
$$

$$
+\left[\begin{array}{ccccc}
\mathbf{0} & \mathbf{0} & \mathbf{0} & \mathbf{0} & \mathbf{0} \\
\mathbf{0} & \mathbf{0} & \mathbf{0} & \mathbf{0} & \mathbf{0} \\
\mathbf{0} & \mathbf{0} & \mathbf{0} & \mathbf{0} & \mathbf{0} \\
\mathbf{0} & \mathbf{0} & \mathbf{0} & \mathbf{K}_{\phi_{x}, \phi_{x}}^{B} & \mathbf{K}_{\phi_{x}, \phi_{y}}^{B} \\
\mathbf{0} & \mathbf{0} & \mathbf{0} & \left(\mathbf{K}_{\phi_{x}, \phi_{y}}^{B}\right)^{T} & \mathbf{K}_{\phi_{y}, \phi_{y}}^{B}
\end{array}\right]
$$


16-points supported plate on the Pasternak foundation

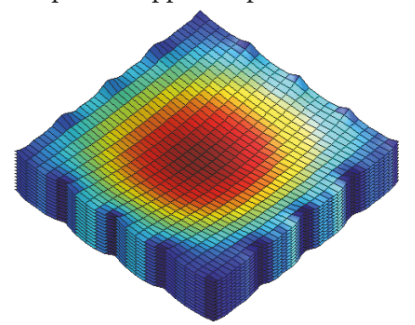

1st mode

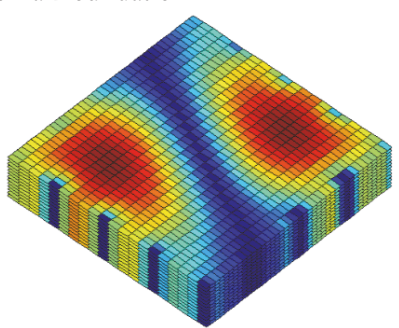

2nd mode

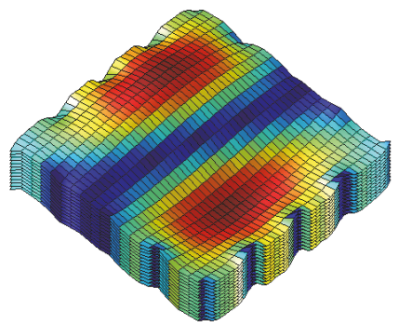

3rd mode

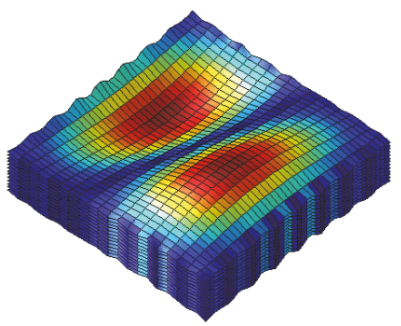

3rd mode

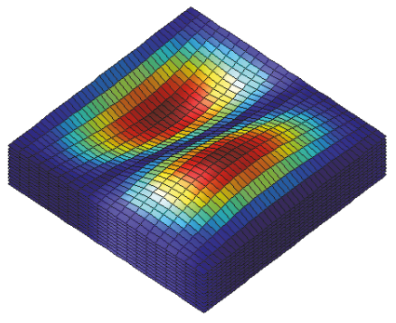

3rd mode

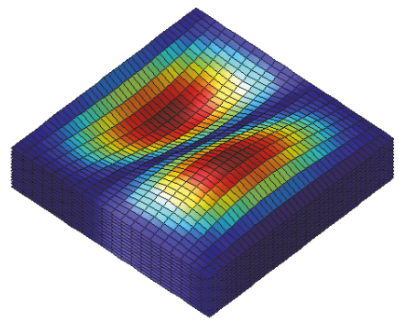

3rd mode

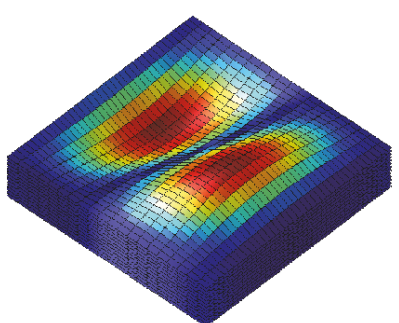

3rd mode

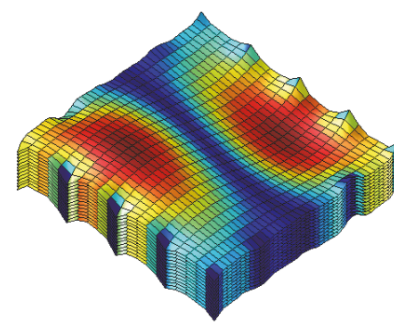

4th mode

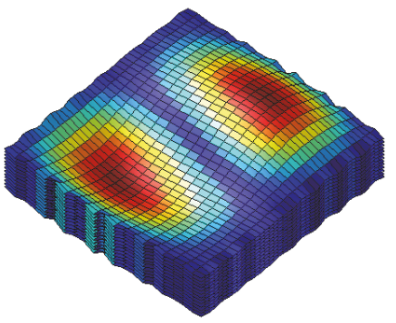

4th mode

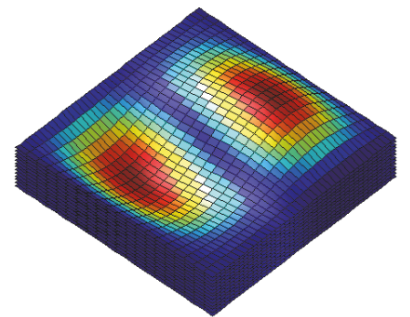

4th mode

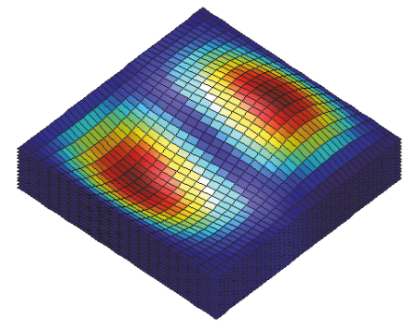

4th mode

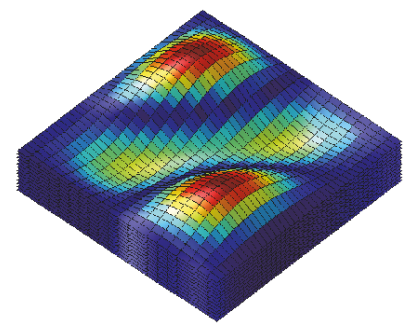

4th mode

FIgURE 12: Mode shapes of multipoints supported laminated plate on the Pasternak foundation. 
Shock and Vibration

19

$$
\begin{aligned}
& +\left[\begin{array}{ccccc}
\mathbf{0} & \mathbf{0} & \mathbf{0} & \mathbf{K}_{u, \phi_{x}}^{B S} & \mathbf{K}_{u, \phi_{y}}^{B S} \\
\mathbf{0} & \mathbf{0} & \mathbf{0} & \mathbf{K}_{v, \phi_{x}}^{B S} & \mathbf{K}_{v, \phi_{y}}^{B S} \\
\mathbf{0} & \mathbf{0} & \mathbf{0} & \mathbf{0} & \mathbf{0} \\
\left(\mathbf{K}_{u, \phi_{x}}^{B S}\right)^{T} & \left(\mathbf{K}_{u, \phi_{y}}^{B S}\right)^{T} & \mathbf{0} & \mathbf{0} & \mathbf{0} \\
\left(\mathbf{K}_{v, \phi_{x}}^{B S}\right)^{T} & \left(\mathbf{K}_{v, \phi_{y}}^{B S}\right)^{T} & \mathbf{0} & \mathbf{0} & \mathbf{0}
\end{array}\right] \\
& \mathbf{K}_{\phi_{y}, \phi_{y}}^{S}=\int_{0}^{a} \int_{0}^{b}\left\{\kappa A_{44} \mathbf{P}^{2}\right\} d x d y, \\
& \mathbf{K}_{\phi_{x}, \phi_{x}}^{B}=\int_{0}^{a} \int_{0}^{b}\left\{D_{11}\left(\frac{\partial \mathbf{P}}{\partial x}\right)^{2}+D_{66}\left(\frac{\partial \mathbf{P}}{\partial y}\right)^{2}\right. \\
& \left.+2 D_{16}\left(\frac{\partial \mathbf{P}}{\partial x}\right)\left(\frac{\partial \mathbf{P}}{\partial y}\right)\right\} d x d y, \\
& +\left[\begin{array}{ccccc}
\mathbf{K}_{u, u}^{S P} & \mathbf{0} & \mathbf{0} & \mathbf{0} & \mathbf{0} \\
\mathbf{0} & \mathbf{K}_{v, v}^{S P} & \mathbf{0} & \mathbf{0} & \mathbf{0} \\
\mathbf{0} & \mathbf{0} & \mathbf{K}_{w, w}^{U_{f}}+\mathbf{K}_{w, w}^{S P} & \mathbf{0} & \mathbf{0} \\
\mathbf{0} & \mathbf{0} & \mathbf{0} & \mathbf{K}_{\phi_{x}, \phi_{x}}^{S P} & \mathbf{0} \\
\mathbf{0} & \mathbf{0} & \mathbf{0} & \mathbf{0} & \mathbf{K}_{\phi_{y}, \phi_{y}}^{S P}
\end{array}\right] \\
& \mathbf{K}_{\phi_{x}, \phi_{y}}^{B}=\int_{0}^{a} \int_{0}^{b}\left\{D_{16}\left(\frac{\partial \mathbf{P}}{\partial x}\right)^{2}+D_{26}\left(\frac{\partial \mathbf{P}}{\partial y}\right)^{2}\right. \\
& \left.+D_{12}\left(\frac{\partial \mathbf{P}}{\partial x}\right)\left(\frac{\partial \mathbf{P}}{\partial y}\right)+D_{66}\left(\frac{\partial \mathbf{P}}{\partial x}\right)\left(\frac{\partial \mathbf{P}}{\partial y}\right)\right\} d x d y, \\
& \mathbf{K}_{\phi_{y}, \phi_{y}}^{B}=\int_{0}^{a} \int_{0}^{b}\left\{D_{66}\left(\frac{\partial \mathbf{P}}{\partial x}\right)^{2}+D_{22}\left(\frac{\partial \mathbf{P}}{\partial y}\right)^{2}\right. \\
& \mathbf{K}_{u, u}^{S} \int_{0}^{a} \int_{0}^{b}\left\{A_{11}\left(\frac{\partial \mathbf{P}}{\partial x}\right)^{2}+A_{66}\left(\frac{\partial \mathbf{P}}{\partial y}\right)^{2}\right. \\
& \left.+2 D_{26}\left(\frac{\partial \mathbf{P}}{\partial x}\right)\left(\frac{\partial \mathbf{P}}{\partial y}\right)\right\} d x d y, \\
& \left.+2 A_{16}\left(\frac{\partial \mathbf{P}}{\partial x}\right)\left(\frac{\partial \mathbf{P}}{\partial y}\right)\right\} d x d y \\
& \mathbf{K}_{u, v}^{S} \int_{0}^{a} \int_{0}^{b}\left\{A_{16}\left(\frac{\partial \mathbf{P}}{\partial x}\right)^{2}+A_{26}\left(\frac{\partial \mathbf{P}}{\partial y}\right)^{2}\right. \\
& \left.+A_{12}\left(\frac{\partial \mathbf{P}}{\partial x}\right)\left(\frac{\partial \mathbf{P}}{\partial y}\right)+A_{66}\left(\frac{\partial \mathbf{P}}{\partial x}\right)\left(\frac{\partial \mathbf{P}}{\partial y}\right)\right\} d x d y, \\
& \mathbf{K}_{v, v}^{S}=\int_{0}^{a} \int_{0}^{b}\left\{A_{66}\left(\frac{\partial \mathbf{P}}{\partial x}\right)^{2}+A_{22}\left(\frac{\partial \mathbf{P}}{\partial y}\right)^{2}\right. \\
& \left.+2 A_{26}\left(\frac{\partial \mathbf{P}}{\partial x}\right)\left(\frac{\partial \mathbf{P}}{\partial y}\right)\right\} d x d y \\
& \mathbf{K}_{u, \phi_{x}}^{B S}=\int_{0}^{a} \int_{0}^{b}\left\{B_{11}\left(\frac{\partial \mathbf{P}}{\partial x}\right)^{2}+B_{66}\left(\frac{\partial \mathbf{P}}{\partial y}\right)^{2}\right. \\
& \left.+2 B_{16}\left(\frac{\partial \mathbf{P}}{\partial x}\right)\left(\frac{\partial \mathbf{P}}{\partial y}\right)\right\} d x d y, \\
& \mathbf{K}_{u, \phi_{y}}^{B S}=\int_{0}^{a} \int_{0}^{b}\left\{B_{16}\left(\frac{\partial \mathbf{P}}{\partial x}\right)^{2}+B_{26}\left(\frac{\partial \mathbf{P}}{\partial y}\right)^{2}\right. \\
& \left.+B_{12}\left(\frac{\partial \mathbf{P}}{\partial x}\right)\left(\frac{\partial \mathbf{P}}{\partial y}\right)+B_{66}\left(\frac{\partial \mathbf{P}}{\partial x}\right)\left(\frac{\partial \mathbf{P}}{\partial y}\right)\right\} d x d y, \\
& \mathbf{K}_{v, \phi_{x}}^{B S}=\int_{0}^{a} \int_{0}^{b}\left\{B_{16}\left(\frac{\partial \mathbf{P}}{\partial x}\right)^{2}+B_{26}\left(\frac{\partial \mathbf{P}}{\partial y}\right)^{2}\right. \\
& \left.+B_{12}\left(\frac{\partial \mathbf{P}}{\partial x}\right)\left(\frac{\partial \mathbf{P}}{\partial y}\right)+B_{66}\left(\frac{\partial \mathbf{P}}{\partial x}\right)\left(\frac{\partial \mathbf{P}}{\partial y}\right)\right\} d x d y, \\
& \mathbf{K}_{v, \phi_{y}}^{B S}=\int_{0}^{a} \int_{0}^{b}\left\{B_{66}\left(\frac{\partial \mathbf{P}}{\partial x}\right)^{2}+B_{22}\left(\frac{\partial \mathbf{P}}{\partial y}\right)^{2}\right. \\
& \left.+2 B_{26}\left(\frac{\partial \mathbf{P}}{\partial x}\right)\left(\frac{\partial \mathbf{P}}{\partial y}\right)\right\} d x d y, \\
& \mathbf{K}_{w, w}^{U_{f}}=\int_{0}^{a} \int_{0}^{b}\left\{K_{W} \mathbf{P}^{2}+K_{S}\left(\frac{\partial \mathbf{P}}{\partial x}\right)^{2}\right. \\
& \left.+K_{S}\left(\frac{\partial \mathbf{P}}{\partial y}\right)^{2}\right\} d x d y .
\end{aligned}
$$

For the elastic uniform boundary conditions of the plate, the stiffness matrix $\mathbf{K}^{S P 1}$ can be expressed as

$$
\begin{aligned}
& \mathbf{K}_{u, u}^{S P 1}=\int_{-h / 2}^{+h / 2}\{\int_{0}^{b} \underbrace{k_{x 0}^{u} \mathbf{P}^{2}}_{x=0} d y+\int_{0}^{b} \underbrace{k_{x a}^{u} \mathbf{P}^{2}}_{x=a} d y \\
& +\int_{0}^{a} \underbrace{k_{y 0}^{u} \mathbf{P}^{2}}_{y=0} d x+\int_{0}^{a} \underbrace{k_{y b}^{u} \mathbf{P}^{2} d x}_{y=b}\} d z,
\end{aligned}
$$




$$
\begin{aligned}
& \mathbf{K}_{v, v}^{S P 1}=\int_{-h / 2}^{+h / 2}\{\int_{0}^{b} \underbrace{k_{x 0}^{v} \mathbf{P}^{2}}_{x=0} d y+\int_{0}^{b} \underbrace{k_{x a}^{v} \mathbf{P}^{2}}_{x=a} d y \\
& +\int_{0}^{a} \underbrace{k_{y 0}^{v} \mathbf{P}^{2}}_{y=0} d x+\int_{0}^{a} \underbrace{k_{y b}^{v} \mathbf{P}^{2}}_{y=b} d x\} d z \\
& \mathbf{K}_{w, w}^{S P 1}=\int_{-h / 2}^{+h / 2}\{\int_{0}^{b} \underbrace{k_{x 0}^{w} \mathbf{P}^{2}}_{x=0} d y+\int_{0}^{b} \underbrace{k_{x a}^{w} \mathbf{P}^{2}}_{x=a} d y \\
& +\int_{0}^{a} \underbrace{k_{y 0}^{w} \mathbf{P}^{2}}_{y=0} d x+\int_{0}^{a} \underbrace{k_{y b}^{w} \mathbf{P}^{2}}_{y=b} d x\} d z, \\
& \mathbf{K}_{\phi_{x}, \phi_{x}}^{S P 1}=\int_{-h / 2}^{+h / 2}\{\int_{0}^{b} \underbrace{K_{x 0}^{\phi_{x}} \mathbf{P}^{2}}_{x=0} d y+\int_{0}^{b} \underbrace{K_{x a}^{\phi_{x}} \mathbf{P}^{2}}_{x=a} d y \\
& +\int_{0}^{a} \underbrace{K_{y 0}^{\phi_{x}} \mathbf{P}^{2}}_{y=0} d x+\int_{0}^{a} \underbrace{K_{y b}^{\phi_{x}} \mathbf{P}^{2}}_{y=b} d x\} d z, \\
& \mathbf{K}_{\phi_{y}, \phi_{y}}^{S P 1}=\int_{-h / 2}^{+h / 2}\{\int_{0}^{b} \underbrace{K_{x 0}^{\phi_{y}} \mathbf{P}^{2}}_{x=0} d y+\int_{0}^{b} \underbrace{K_{x a}^{\phi_{y}} \mathbf{P}^{2}}_{x=a} d y \\
& +\int_{0}^{a} \underbrace{K_{y 0}^{\phi_{y}} \mathbf{P}^{2}}_{y=0} d x+\int_{0}^{a} \underbrace{K_{y b}^{\phi_{y}} \mathbf{P}^{2}}_{y=b} d x\} d z .
\end{aligned}
$$

For the elastic multipoints supported boundary conditions of the plate, the stiffness matrix $\mathbf{K}^{S P 2}$ can be expressed as

$$
\begin{aligned}
& \mathbf{K}_{u, u}^{S P 2} \\
& =\sum_{r=0}^{N R}\{\underbrace{k_{x 0}^{u} \mathbf{P}^{2}}_{x=0, y=y_{r}}+\underbrace{k_{x a}^{u} \mathbf{P}^{2}}_{x=a, y=y_{r}}+\underbrace{k_{y 0}^{u} \mathbf{P}^{2}}_{x=x_{r}, y=0}+\underbrace{k_{y b}^{u} \mathbf{P}^{2}}_{x=x_{r}, y=b}\}, \\
& \left.\mathbf{K}_{v, v}^{S P 2}\right\} \\
& \quad=\sum_{r=0}^{N R}\{\underbrace{k_{x 0}^{v} \mathbf{P}^{2}}_{x=0, y=y_{r}}+\underbrace{k_{x a}^{v} \mathbf{P}^{2}}_{x=a, y=y_{r}}+\underbrace{k_{y 0}^{v} \mathbf{P}^{2}}_{x=x_{r}, y=0}+\underbrace{k_{y b}^{v} \mathbf{P}^{2}}_{x=x_{r}, y=b}\}, \\
& \quad=\sum_{r=0}^{S P 2}\{\underbrace{k_{x 0}^{w} \mathbf{P}^{2}}_{x=0, y=y_{r}}+\underbrace{k_{x a}^{w} \mathbf{P}^{2}}_{x=a, y=y_{r}}+\underbrace{k_{y 0}^{w} \mathbf{P}^{2}}_{x=x_{r}, y=0}+\underbrace{k_{y b}^{w} \mathbf{P}^{2}}_{x=x_{r}, y=b}\},
\end{aligned}
$$

$$
\begin{aligned}
& \mathbf{K}_{\phi_{x}, \phi_{x}}^{S P 2} \\
& \quad=\sum_{r=0}^{N R}\{\underbrace{K_{x 0}^{\phi_{x}} \mathbf{P}^{2}}_{x=0, y=y_{r}}+\underbrace{K_{x a}^{\phi_{x}} \mathbf{P}^{2}}_{x=a, y=y_{r}}+\underbrace{K_{y 0}^{\phi_{x}} \mathbf{P}^{2}}_{x=x_{r}, y=0}+\underbrace{K_{y b}^{\phi_{x}} \mathbf{P}^{2}}_{x=x_{r}, y=b}\}, \\
& \mathbf{K}_{\phi_{y}, \phi_{y}}^{S P 2} \\
& \quad=\sum_{r=0}^{N R}\{\underbrace{K_{x 0}^{\phi_{y}} \mathbf{P}^{2}}_{x=0, y=y_{r}}+\underbrace{K_{x a}^{\phi_{y}} \mathbf{P}^{2}}_{x=a, y=y_{r}}+\underbrace{K_{y 0}^{\phi_{y}} \mathbf{P}^{2}}_{x=x_{r}, y=0}+\underbrace{K_{y b}^{\phi_{y}} \mathbf{P}^{2}}_{x=x_{r}, y=b}\} .
\end{aligned}
$$

The specific expressions of mass matrix $\mathbf{M}$ can be written as follows:

$$
\begin{aligned}
\mathbf{M} & =\left[\begin{array}{ccccc}
\mathbf{M}_{u, u} & \mathbf{0} & \mathbf{0} & \mathbf{M}_{u, \phi_{x}} & \mathbf{0} \\
\mathbf{0} & \mathbf{M}_{v, v} & \mathbf{0} & \mathbf{0} & \mathbf{M}_{v, \phi_{y}} \\
\mathbf{0} & \mathbf{0} & \mathbf{M}_{w, w} & \mathbf{0} & \mathbf{0} \\
\mathbf{M}_{u, \phi_{x}}^{T} & \mathbf{0} & \mathbf{0} & \mathbf{M}_{\phi_{x}, \phi_{x}} & \mathbf{0} \\
\mathbf{0} & \mathbf{M}_{v, \phi_{y}}^{T} & \mathbf{0} & \mathbf{0} & \mathbf{M}_{\phi_{y}, \phi_{y}}
\end{array}\right] \\
& =\left[\begin{array}{ccccc}
I_{0} \mathbf{P}^{2} & \mathbf{0} & \mathbf{0} & I_{1} \mathbf{P}^{2} & \mathbf{0} \\
\mathbf{0} & I_{0} \mathbf{P}^{2} & \mathbf{0} & \mathbf{0} & I_{1} \mathbf{P}^{2} \\
\mathbf{0} & \mathbf{0} & I_{0} \mathbf{P}^{2} & \mathbf{0} & \mathbf{0} \\
\left(I_{1} \mathbf{P}^{2}\right)^{T} & \mathbf{0} & \mathbf{0} & I_{2} \mathbf{P}^{2} & \mathbf{0} \\
0 & \left(I_{1} \mathbf{P}^{2}\right)^{T} & \mathbf{0} & \mathbf{0} & I_{2} \mathbf{P}^{2}
\end{array}\right] .
\end{aligned}
$$

The specific expressions of mass matrix $\overline{\mathbf{F}}$ can be written as follows:

$$
\overline{\mathbf{F}}=\left[\begin{array}{llllll}
f_{u} \mathbf{P} & f_{v} \mathbf{P} & f_{w} \mathbf{P} & f_{\phi_{x}} \mathbf{P} & f_{\phi_{y}} \mathbf{P}
\end{array}\right]
$$

\section{Nomenclature}

$a, b, h: \quad$ Rectangular plate dimensions

$k_{u}, k_{v}, k_{w}: \quad$ Linear springs stiffness

$x, y, z: \quad$ Plate coordinate variables

$K_{x}, K_{y}: \quad$ Rotational springs stiffness

$u, v, w: \quad$ Middle surface displacements

$\phi_{x}, \phi_{y}$ : Rotations of transverse normal

$\varepsilon_{x x}^{0}, \varepsilon_{y y}^{0}, \gamma_{x y}^{0}: \quad$ Normal and shear strains

$\gamma_{x z}, \gamma_{y z}: \quad$ Transverse shear strains

$\chi_{x x}, \chi_{y y}, \chi_{x y}$ : Curvature and twist changes

$\sigma_{x x}, \sigma_{y y}: \quad$ Normal stresses

$\tau_{y z}, \tau_{x z}, \tau_{x y}:$ Shear stresses

$E_{1}, E_{2}$ : $\quad$ Young's moduli with respect to principle axes of lamina 


$\begin{array}{ll}G_{12}, G_{13}, G_{23}: & \text { Shear moduli } \\ \mu_{12}, \mu_{21}: & \text { Poisson's ratios } \\ N_{x}, N_{y}, N_{x y}: & \text { Normal and shear force result- } \\ \theta: & \text { ants } \\ M_{x}, M_{y}, M_{x y}: & \begin{array}{l}\text { Fiber laying angle } \\ \text { Bending and twisting moment } \\ \text { resultants }\end{array} \\ Q_{x}, Q_{y}: & \text { Transverse shear force } \\ A_{i j}, D_{i j}, B_{i j}: & \text { Extensional, bending, and exten- } \\ & \text { sional-bending stiffness coeff- } \\ \overline{Q_{i j}^{k}}: & \text { cients } \\ A_{m n}^{i}, B_{m n}^{i}, C_{m n}^{i}, D_{m n}^{i}, E_{m n}^{i}: & \text { Lamina stiffness coefficients } \\ Q_{p l}^{k}: & \text { Fourier coefficients expansions } \\ \mathbf{A}_{m n}, \mathbf{B}_{m n}, \mathbf{C}_{m n}, \mathbf{D}_{m n}, \mathbf{E}_{m n}: & \text { Fourierial coefficients } \\ \mathbf{P}: & \text { Fourier series expansions vector } \\ \mathbf{K}, \mathbf{M}, \mathbf{G}, \overline{\mathbf{F}}: & \text { Stiffness, mass, coefficient, and } \\ & \text { force matrices } \\ \kappa: & \text { Shear correction factor } \\ k_{W}=K_{W} a^{4} / E_{2} h^{3}: & \text { Nondimensional Winkler foun- } \\ & \text { dation parameter } \\ L_{i j}: & \text { Linear differential operator } \\ k_{S}=K_{S} a^{4} / E_{2} h^{3}: & \text { Nondimensional Pasternak foun- } \\ F: & \text { dation parameter } \\ \Omega=\omega a^{2} \sqrt{\rho / E_{2} h^{2}:} & \text { Normal harmonic point force } \\ K_{w}, K_{s}: & \text { Nondimensional frequency pa- } \\ & \text { rameter } \\ & \text { Linear Winkler and Pasternak } \\ \text { foundation parameters. }\end{array}$

\section{Conflicts of Interest}

The authors declare that there are no conflicts of interest regarding the publication of this paper.

\section{Acknowledgments}

The authors gratefully acknowledge the financial support from the National Natural Science Foundation of China (no. 51679056) and Natural Science Foundation of Heilongjiang Province of China (E2016024).

\section{References}

[1] P. A. A. Laura, R. H. Gutierrez, R. Carnicer, and H. C. Sanzi, "Free vibrations of a solid circular plate of linearly varying thickness and attached to a winkler foundation," Journal of Sound and Vibration, vol. 144, no. 1, pp. 149-161, 1991.

[2] K. M. Liew, J.-B. Han, Z. M. Xiao, and H. Du, "Differential quadrature method for Mindlin plates on Winkler foundations," International Journal of Mechanical Sciences, vol. 38, no. 4, pp. 405-421, 1996.

[3] U. S. Gupta, R. Lal, and S. K. Jain, "Effect of elastic foundation on axisymmetric vibrations of polar orthotropic circular plates of variable thickness," Journal of Sound and Vibration, vol. 139, no. 3, pp. 503-513, 1990.
[4] Y. Xiang, "Vibration of rectangular Mindlin plates resting on non-homogenous elastic foundations," International Journal of Mechanical Sciences, vol. 45, no. 6-7, pp. 1229-1244, 2003.

[5] D. Younesian, H. Askari, Z. Saadatnia, and M. KalamiYazdi, "Frequency analysis of strongly nonlinear generalized Duffing oscillators using HE's frequency-amplitude formulation and HE's energy balance method," Computers \& Mathematics with Applications, vol. 59, no. 9, pp. 3222-3228, 2010.

[6] D. Younesian, H. Askari, Z. Saadatnia, and E. Esmailzadeh, "Analytical solutions for oscillation of rectangular plate on a nonlinear winkler foundation," in Proceedings of the ASME 2011 International Design Engineering Technical Conferences and Computers and Information in Engineering Conference, IDETC/CIE 2011, pp. 755-760, August 2011.

[7] M. Ansari, E. Esmailzadeh, and D. Younesian, "Internalexternal resonance of beams on non-linear viscoelastic foundation traversed by moving load," Nonlinear Dynamics, vol. 61, no. 1-2, pp. 163-182, 2010.

[8] M. Ansari, E. Esmailzadeh, and D. Younesian, "Frequency analysis of finite beams on nonlinear KelvinVoight foundation under moving loads," Journal of Sound and Vibration, vol. 330, no. 7, pp. 1455-1471, 2011.

[9] Z. Saadatnia, H. Askari, and E. Esmailzadeh, "Multi-frequency excitation of microbeams supported by Winkler and Pasternak foundations," Journal of Vibration and Control, 2017.

[10] A. Ghannadiasl and M. Mofid, "Free vibration analysis of general stepped circular plates with internal elastic ring support resting on Winkler foundation by green function method," Mechanics Based Design of Structures and Machines, vol. 44, no. 3, pp. 212-230, 2016.

[11] J. Kaplunov, D. A. Prikazchikov, and G. A. Rogerson, "Edge bending wave on a thin elastic plate resting on a Winkler foundation," Proceedings of the Royal Society of London A, 2016.

[12] K. Özgan and A. T. Daloğlu, "Free vibration analysis of thick plates resting on Winkler elastic foundation," Challenge, vol. 1, no. 2, pp. 78-83, 2015.

[13] K. Nedri, N. El Meiche, and A. Tounsi, "Free vibration analysis of laminated composite plates resting on elastic foundations by using a refined hyperbolic shear deformation theory," Mechanics of Composite Materials, vol. 49, no. 6, pp. 629-640, 2014.

[14] A. K. Baltacıoğlu, Ö. Civalek, B. Akgöz, and F. Demir, "Large deflection analysis of laminated composite plates resting on nonlinear elastic foundations by the method of discrete singular convolution," International Journal of Pressure Vessels and Piping, vol. 88, no. 8-9, pp. 290-300, 2011.

[15] B. N. Singh, A. Lal, and R. Kumar, "Post buckling response of laminated composite plate on elastic foundation with random system properties," Communications in Nonlinear Science and Numerical Simulation, vol. 14, no. 1, pp. 284-300, 2009.

[16] K. Malekzadeh, S. M. R. Khalili, and P. Abbaspour, "Vibration of non-ideal simply supported laminated plate on an elastic foundation subjected to in-plane stresses," Composite Structures, vol. 92, no. 6, pp. 1478-1484, 2010.

[17] A. Kutlu, B. Uğurlu, M. H. Omurtag, and A. Ergin, "Dynamic response of Mindlin plates resting on arbitrarily orthotropic Pasternak foundation and partially in contact with fluid," Ocean Engineering, vol. 42, pp. 112-125, 2012.

[18] F. Tornabene, N. Fantuzzi, E. Viola, and J. N. Reddy, "WinklerPasternak foundation effect on the static and dynamic analyses of laminated doubly-curved and degenerate shells and panels," Composites Part B: Engineering, vol. 57, pp. 269-296, 2014. 
[19] H. N. Jahromi, M. M. Aghdam, and A. Fallah, "Free vibration analysis of Mindlin plates partially resting on Pasternak foundation," International Journal of Mechanical Sciences, vol. 75, pp. $1-7,2013$.

[20] Y. Li and J. Zhang, "Free vibration analysis of magnetoelectroelastic plate resting on a Pasternak foundation," Smart Materials and Structures, vol. 23, no. 2, article 025002, 2014.

[21] S. M. Khalili, P. Abbaspour, and K. Malekzadeh Fard, "Buckling of non-ideal simply supported laminated plate on Pasternak foundation," Applied Mathematics and Computation, vol. 219, no. 12, pp. 6420-6430, 2013.

[22] M. Dehghany and A. Farajpour, "Free vibration of simply supported rectangular plates on pasternak foundation: an exact and three-dimensional solution," Engineering Solid Mechanics, vol. 2, no. 1, pp. 29-42, 2014.

[23] C. R. Briscoe, S. C. Mantell, and J. H. Davidson, "Buckling of a plate on a Pasternak foundation under uniform in-plane bending loads," International Journal of Structural Stability and Dynamics, vol. 13, no. 3, Article ID 1250070, 2013.

[24] H.-T. Thai, M. Park, and D.-H. Choi, "A simple refined theory for bending, buckling, and vibration of thick plates resting on elastic foundation," International Journal of Mechanical Sciences, vol. 73, pp. 40-52, 2013.

[25] A. S. Idowu, E. B. Are, K. M. Joseph, and S. K. Daniel, "Dynamic effects of viscous damping on isotropic rectangular plates resting on pasternak foundation, subjected to moving loads," International Journals of Mathematics and Statistical Studies, vol. 1, no. 2, pp. 12-19, 2013.

[26] E. Bahmyari and M. R. Khedmati, "Vibration analysis of nonhomogeneous moderately thick plates with point supports resting on Pasternak elastic foundation using element free Galerkin method," Engineering Analysis with Boundary Elements, vol. 37, no. 10, pp. 1212-1238, 2013.

[27] Y. Kiani, E. Bagherizadeh, and M. R. Eslami, "Thermal and mechanical buckling of sandwich plates with FGM face sheets resting on the Pasternak elastic foundation," Proceedings of the Institution of Mechanical Engineers, Part C: Journal of Mechanical Engineering Science, vol. 226, no. 1, pp. 32-41, 2012.

[28] M. Pradhan, M. K. Mishra, and P. R. Dash, "Free vibration analysis of an asymmetric sandwich beam resting on a variable pasternak foundation," Procedia Engineering, vol. 144, pp. 116$123,2016$.

[29] V. Stojanović and M. D. Petković, "Nonlinear dynamic analysis of damaged Reddy-Bickford beams supported on an elastic Pasternak foundation," Journal of Sound and Vibration, vol. 385, pp. 239-266, 2016.

[30] H. Zhang, D. Shi, and Q. Wang, "An improved Fourier series solution for free vibration analysis of the moderately thick laminated composite rectangular plate with non-uniform boundary conditions," International Journal of Mechanical Sciences, vol. 121, pp. 1-20, 2017.

[31] H. Askari, Z. Saadatnia, E. Esmailzadeh, and D. Younesian, "Multi-frequency excitation of stiffened triangular plates for large amplitude oscillations," Journal of Sound and Vibration, vol. 333, no. 22, pp. 5817-5835, 2014.

[32] A. Borković, N. Mrda, and S. Kovačević, "Dynamical analysis of stiffened plates using the compound strip method," Engineering Structures, vol. 50, pp. 56-67, 2013.

[33] T. Nguyen-Thoi, T. Bui-Xuan, P. Phung-Van, H. Nguyen-Xuan, and P. Ngo-Thanh, "Static, free vibration and buckling analyses of stiffened plates by CS-FEM-DSG3 using triangular elements," Computers \& Structures, vol. 125, pp. 100-113, 2013.
[34] M. Tekgoz, Y. Garbatov, and C. G. Soares, Finite Element Modelling of The Ultimate Strength of Stiffened Plates with Residual Stresses, 2014, Tree Biotechnology.

[35] T. Bose and A. R. Mohanty, "Vibration analysis of a rectangular thin isotropic plate with a part-through surface crack of arbitrary orientation and position," Journal of Sound and Vibration, vol. 332, no. 26, pp. 7123-7141, 2013.

[36] N. Fantuzzi, F. Tornabene, and E. Viola, "Four-parameter functionally graded cracked plates of arbitrary shape: a GDQFEM solution for free vibrations," Mechanics of Advanced Materials and Structures, vol. 23, no. 1, pp. 89-107, 2016.

[37] P. V. Joshi, N. K. Jain, and G. D. Ramtekkar, "Analytical modeling and vibration analysis of internally cracked rectangular plates," Journal of Sound and Vibration, vol. 333, no. 22, pp. 58515864, 2014.

[38] T. Nguyen-Thoi, T. Rabczuk, T. Lam-Phat, V. Ho-Huu, and P. Phung-Van, "Free vibration analysis of cracked Mindlin plate using an extended cell-based smoothed discrete shear gap method (XCS-DSG3)," Theoretical and Applied Fracture Mechanics, vol. 72, pp. 150-163, 2014.

[39] R. R. Ahmad, "Plastic collapse load of corroded steel plates," Sadhana-Academy Proceedings in Engineering Sciences, vol. 37, no. 3, pp. 341-349, 2012.

[40] A. Eslami-Majd and A. Rahbar-Ranji, "Free vibration analysis of corroded steel plates," Journal of Mechanical Science and Technology, vol. 28, no. 6, pp. 2081-2088, 2014.

[41] A. Eslami-majd and A. Rahbar-Ranji, "Blast response of corroded steel plates," Journal of Mechanical Science and Technology, vol. 28, no. 5, pp. 1683-1690, 2014.

[42] A. Eslami-Majd and A. Rahbar-Ranji, "Deformation behaviour of corroded plates subjected to blast loading," Ships and Offshore Structures, vol. 10, no. 1, pp. 79-93, 2015.

[43] A. Rahbar-Ranji, "Elastic tripping analysis of corroded stiffeners in stiffened plate with irregular surfaces," Journal of Mechanical Science and Technology, vol. 28, no. 9, pp. 36293636, 2014.

[44] W. L. Li, "Vibration analysis of rectangular plates with general elastic boundary supports," Journal of Sound and Vibration, vol. 273, no. 3, pp. 619-635, 2004.

[45] X. Zhang and W. L. Li, "Vibrations of rectangular plates with arbitrary non-uniform elastic edge restraints," Journal of Sound and Vibration, vol. 326, no. 1-2, pp. 221-234, 2009.

[46] D. Shao, F. Hu, Q. Wang, F. Pang, and S. Hu, "Transient response analysis of cross-ply composite laminated rectangular plates with general boundary restraints by the method of reverberation ray matrix," Composite Structures, vol. 152, pp. 168-182, 2016.

[47] D. Shao, S. Hu, Q. Wang, and F. Pang, "A unified analysis for the transient response of composite laminated curved beam with arbitrary lamination schemes and general boundary restraints," Composite Structures, vol. 154, pp. 507-526, 2016.

[48] Q. Wang, D. Shi, Q. Liang, and F. Ahad, "A unified solution for free in-plane vibration of orthotropic circular, annular and sector plates with general boundary conditions," Applied Mathematical Modelling, vol. 40, no. 21-22, pp. 9228-9253, 2016.

[49] Q. Wang, D. Shi, Q. Liang, and F. Pang, "A unified solution for vibration analysis of moderately thick, functionally graded rectangular plates with general boundary restraints and internal line supports," Mechanics of Advanced Materials and Structures, vol. 24, no. 11, pp. 943-961, 2017. 
[50] Q. Wang, D. Shi, Q. Liang, and X. Shi, "A unified solution for vibration analysis of functionally graded circular, annular and sector plates with general boundary conditions," Composites Part B: Engineering, vol. 88, pp. 264-294, 2016.

[51] M. S. Qatu, Vibration of Laminated Shells and Plates, Elsevier, Amsterdam, Holland, 2004.

[52] J. N. Reddy, "Theory and analysis of laminated composite plates," Mechanics of Composite Materials and Structures, pp. 179, 1999.

[53] D. Shao, S. Hu, Q. Wang, and F. Pang, "An enhanced reverberation-ray matrix approach for transient response analysis of composite laminated shallow shells with general boundary conditions," Composite Structures, vol. 162, pp. 133-155, 2017.

[54] D. Shao, S. Hu, Q. Wang, and F. Pang, "Free vibration of refined higher-order shear deformation composite laminated beams with general boundary conditions," Composites Part B: Engineering, vol. 108, pp. 75-90, 2017.

[55] Q. Wang, D. Shi, Q. Liang, and F. Pang, "Free vibrations of composite laminated doubly-curved shells and panels of revolution with general elastic restraints," Applied Mathematical Modelling, vol. 46, pp. 227-262, 2017.

[56] Q. Wang, F. Pang, B. Qin, and Q. Liang, "A unified formulation for free vibration of functionally graded carbon nanotube reinforced composite spherical panels and shells of revolution with general elastic restraints by means of the Rayleigh-Ritz method," Polymer Composites, 2017.

[57] Q. Wang, D. Shi, Q. Liang, and F. Pang, "Free vibration of four-parameter functionally graded moderately thick doublycurved panels and shells of revolution with general boundary conditions," Applied Mathematical Modelling, vol. 42, pp. 705734, 2017.

[58] Q. Wang, D. Shi, F. Pang, and F. Ahad, "Benchmark solution for free vibration of thick open cylindrical shells on Pasternak foundation with general boundary conditions," Meccanica. International Journal of Theoretical and Applied Mechanics, vol. 52, no. 1-2, pp. 457-482, 2017.

[59] Q. Wang, D. Shi, and Q. Liang, "Free vibration analysis of axially loaded laminated composite beams with general boundary conditions by using a modified Fourier-Ritz approach," Journal of Composite Materials, vol. 50, no. 15, pp. 2111-2135, 2016.

[60] D. Shi, Q. Wang, X. Shi, and F. Pang, "A series solution for the in-plane vibration analysis of orthotropic rectangular plates with non-uniform elastic boundary constraints and internal line supports," Archive of Applied Mechanics, vol. 85, no. 1, pp. 51-73, 2015.

[61] D. Shi, Q. Wang, X. Shi, and F. Pang, "An accurate solution method for the vibration analysis of Timoshenko beams with general elastic supports," Proceedings of the Institution of Mechanical Engineers Part C: Journal of Mechanical Engineering Science, vol. 229, no. 13, pp. 2327-2340, 2014.

[62] Q. Wang, D. Shi, Q. Liang, and F. Ahad, "An improved Fourier series solution for the dynamic analysis of laminated composite annular, circular, and sector plate with general boundary conditions," Journal of Composite Materials, vol. 50, no. 30, pp. 41994233, 2016.

[63] M. K. Yazdi and P. H. Tehrani, "Frequency analysis of nonlinear oscillations via the global error minimization," Nonlinear Engineering, vol. 5, no. 2, pp. 87-92, 2016.

[64] Y. Khan, M. Kalami-Yazdi, H. Askari, and Z. Saadatnia, "Dynamic analysis of generalized conservative nonlinear oscillators via frequency amplitude formulation," A rabian Journal for Science and Engineering, vol. 38, no. 1, pp. 175-179, 2013.
[65] Y. Khan, Q. Wu, H. Askari, Z. Saadatnia, and M. Kalami-Yazdi, "Nonlinear vibration analysis of a rigid rod on a circular surface via hamiltonian approach," Mathematical and Computational Applications, vol. 15, no. 5, pp. 974-977, 2010.

[66] H. Zhang, D. Shi, and Q. Wang, "Free vibration analysis of the moderately thick laminated composite rectangular plate on two-parameter elastic foundation with elastic boundary conditions," KnE Materials Science, vol. 1, no. 1, pp. 190-193, 2016.

[67] H.-S. Shen, J.-J. Zheng, and X.-L. Huang, "Dynamic response of shear deformable laminated plates under thermomechanical loading and resting on elastic foundatios," Composite Structures, vol. 60 , no. 1, pp. 57-66, 2003. 


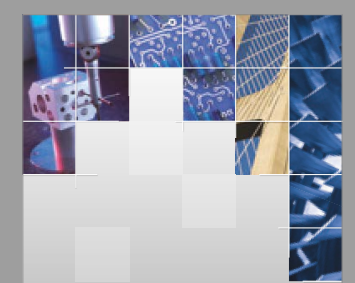

\section{Enfincering}
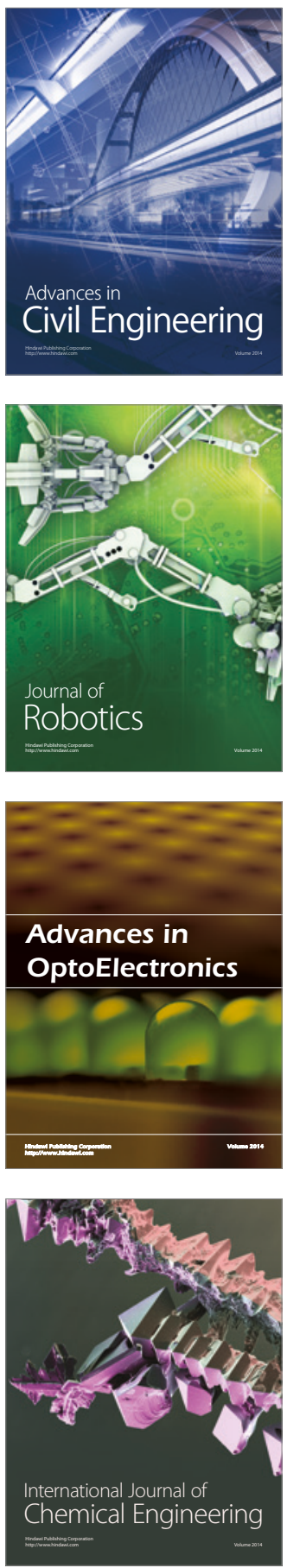

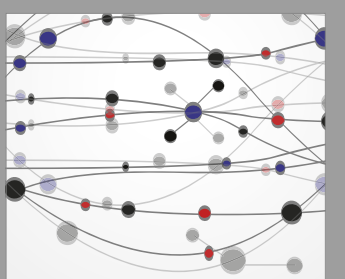

The Scientific World Journal

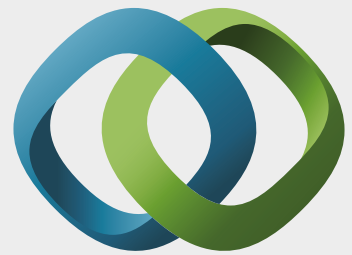

\section{Hindawi}

Submit your manuscripts at

https://www.hindawi.com
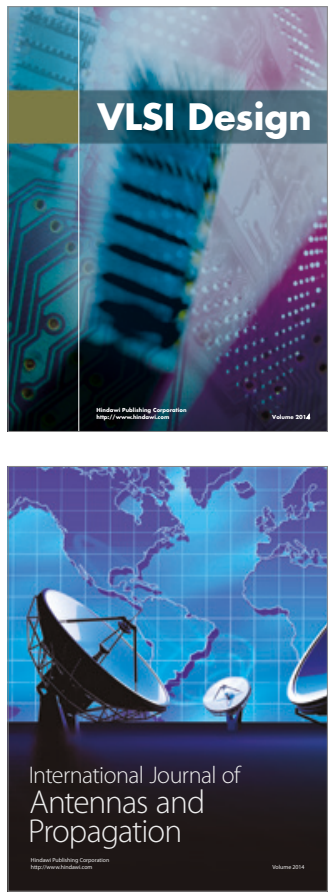

\section{Rotating}

Machinery
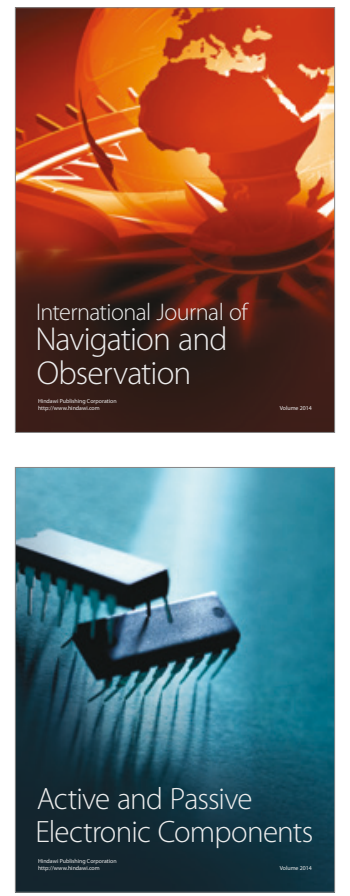
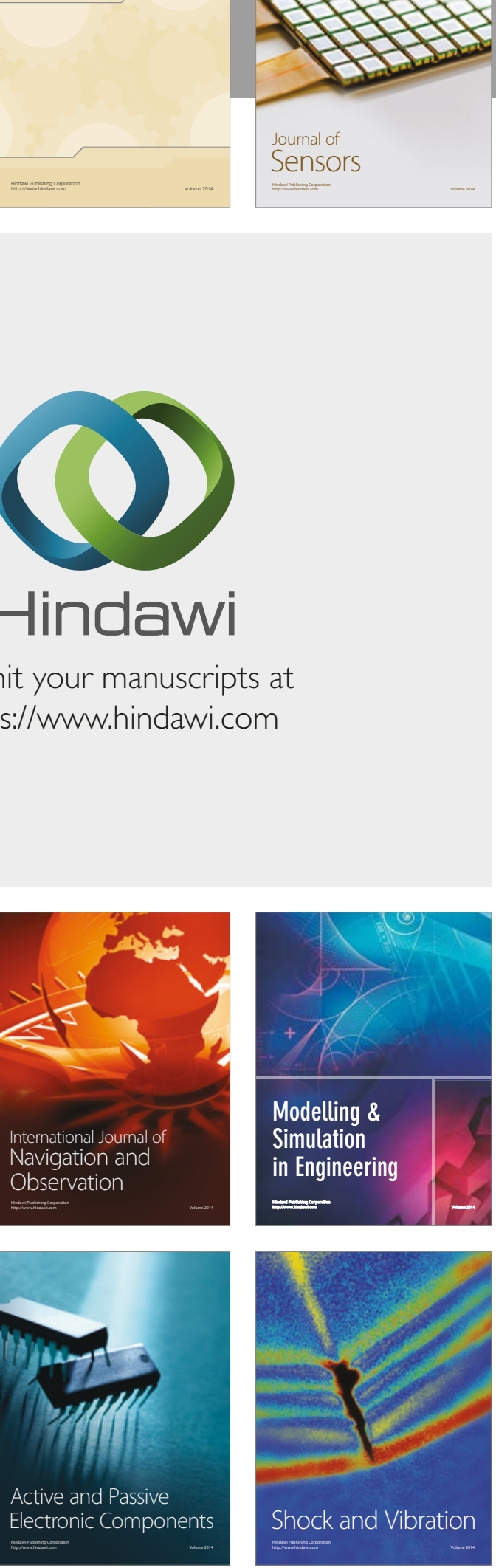
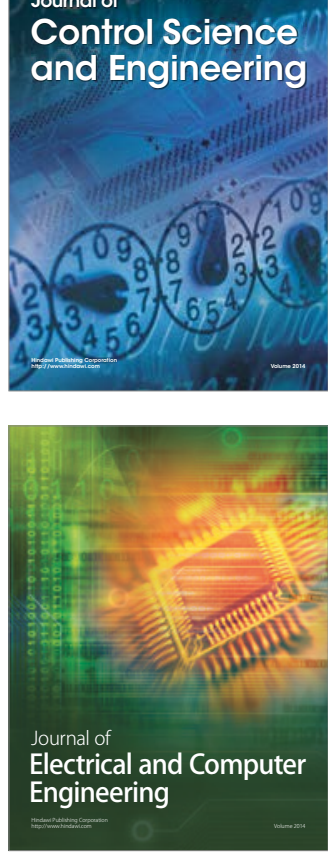

Distributed

Journal of

Control Science

and Engineering
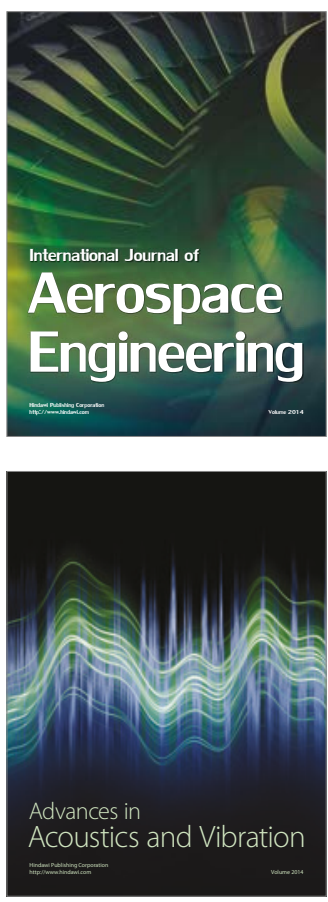

Sensor Networks 